\title{
Auroral precipitation fading before and at substorm onset: ionospheric and geostationary signatures
}

\author{
K. Kauristie ${ }^{1}$, T. I. Pulkkinen ${ }^{1}$, A. Huuskonen ${ }^{1}$, R. J. Pellinen ${ }^{1}$, H. J. Opgenoorth ${ }^{2}$, D. N. Baker ${ }^{3}$, \\ A. Korth ${ }^{4}$, M. Syrjäsuo ${ }^{1}$ \\ ${ }^{1}$ Finnish Meteorological Institute, Department of Geophysics, Helsinki, Finland \\ ${ }^{2}$ Swedish Institute of Space Physics, Uppsala, Sweden (also: visiting Prof. at Finnish Meteorological Institute) \\ ${ }^{3}$ Laboratory for Atmospheric and Space Physics, University of Colorado, Boulder, CO, USA \\ ${ }^{4}$ Max-Planck-Institut fuer Aeronomie, Katlenburg-Lindau, Germany
}

Received: 12 November 1996 / Revised: 3 March 1997 / Accepted: 10 March 1997

\begin{abstract}
Rapid fading of auroral activity a few minutes before substorm breakup has earlier been analyzed in case-studies. Here we report on a study in which all-sky camera (ASC) and magnetic data over 3 years were examined to find breakups that were accompanied by a preceding fading. To illustrate typical features of the fading effect we analyze three events in detail and discuss seven other events to find the spatial and temporal behavior of the fading and the global conditions favoring this phenomenon, which is not associated with every breakup. In these ten events the precipitation diminished typically for about $2 \mathrm{~min}$ and a local breakup followed after 2-3 min. Usually the arc which broke up had faded earlier. Comparison with geostationary electron flux recordings shows that in many cases the global onset had already taken place when the fading was recorded at a different longitude. Thus fading is not just a growth-phase phenomenon as often thought, but can also appear as a precursor of the approaching auroral bulge. The $A E$ index and solarwind data reveal that the fading has a tendency to take place during magnetically disturbed conditions caused by continuous energy input from the solar wind. Furthermore, while a widely recognized phenomenon, we have found that the fading prior to breakup is not a very common feature in the spatio-temporal scale of auroral ASC recordings. In many cases the deepness of the fading had a longitudinal dependence, which leads to the suggestion that this phenomenon is related to azimuthal gradients in the tail magnetic field and/or plasma pressure. Possible scenarios causing fading both before and after the onset are discussed based on a few previously presented theoretical auroral-arc models.
\end{abstract}

Correspondence to: K. Kauristie

\section{Introduction}

In the high-latitude ionosphere during the last few minutes before the substorm breakup the growth phase processes sometimes show puzzling behavior. During this "trigger phase", as first named by Pellinen and Heikkila (1978, 1984), the slow, linear growth phase processes are interrupted when ionospheric activity decreases just before the breakup. Fading is observed both in soft and hard precipitation and in magnetic pulsation and westward electrojet activity (Kauristie et al., 1995). In contrast to the more global growthphase development, fading is typically localized to the onset region (Pellinen and Heikkila, 1978).

In their pioneering work, Pellinen and Heikkila (1978) studied four fading events during the years 1975-76 using numerous ground-based instruments [all-sky cameras (ASC's), photometers, riometers, and backscatter receivers]. They concluded that in recordings with sufficiently high time resolution (some tens of seconds) the fading is "a rather common feature". They pointed out that the fading can appear either as a temporal decrease in the auroral activity prior to the onset or as a dark region travelling ahead of the auroral surge. Making a distinction between these two cases is as difficult as defining the time of the global onset: a longitudinally extended ASC network would be helpful.

Morse and Romick (1982) reported on fading events recorded with a meridian scanning photometer. The durations of the fadings were 4-7 min, a few minutes longer than in the cases analyzed by Pellinen and Heikkila (1978). The photometer recordings revealed periodic fluctuations in the peak intensity of the arc during $\sim 1 \mathrm{~h}$ before the breakup. The fluctuations were typically a superposition of strong long-period variations (period $\sim 10 \mathrm{~min}$ ) and smaller, more rapid variations (period $\sim 1-4 \mathrm{~min}$ ).

An exceptionally clear fading event was recorded on 5 October 1986 by several different instruments, includ- 
ing the EISCAT (European incoherent-scatter) radar in Troms $\varnothing$ (TRO, c.f. Table 2) (Kauristie et al., 1995). The power profile recorded by EISCAT and three ASC frames recorded at Kilpisjärvi (KIL) during this event are shown in Fig. 1. Both EISCAT and ASC recordings show the fading simultaneously. The breakup precipitation after the fading produced increased electron density at exceptionally low altitudes, suggesting that the onset took place in the very close vicinity of the radar beam (Olsson et al., 1996). Thus in this case the fading most probably occurred before the onset.

Kauristie et al. (1995) suggested that the main cause of the fading is in the magnetospheric substorm onset region. Wave-particle interactions in the field-aligned acceleration region at $\leq 1 R_{E}$ are unlikely systematically to deplete the loss-cone and to cause fading along the entire arc. This conclusion is supported by two observations: firstly, EISCAT recorded the fading, although the radar beam was not exactly directed at the visible arc but in the dark region to the north of it. This indicates that the effect has also a considerable latitudinal extent. Secondly, the fading can be observed also in X-ray balloon experiments (Pellinen and Heikkila, 1984), indicating that precipitation at energy levels above $\sim 25 \mathrm{keV}$ fades. Such an effect cannot be caused by acceleration region processes which typically affect energies below $\sim 20 \mathrm{keV}$.

In this paper, which is a follow-up study to Kauristie et al. (1995), we analyze ten carefully selected fading events using both ground-based and geostationary observations. The data set and the instrumentation are reviewed briefly in Sect. 2 and three events are analyzed in detail in Sect. 3. In Sect. 4 the global conditions preceding the fading and the differences and common features of the fading events are discussed. The possible connection of fading with the inductive electric field and azimuthal gradients in the tail magnetic field and plasma pressure are discussed in Sect. 5. The results are summarized in Sect. 6.

\section{Description of the data set}

The events of our data set are listed in Table 1. Event 1 is from the GEOS 2 operation period, event 8 is the one analyzed in detail by Kauristie et al. (1995), and event 10 was recorded in Kiruna (KIR, c.f. Table 2) during the test recordings of the new prototype ASC of the Finnish Meteorological Institute (Pajunpää and Syrjäsuo, 1996). The seven other events were found by examining ASC recordings made during $\sim 500$ substorms during the years 1985-1988 at five stations in northern Finland and Svalbard. We selected the events with special care in order to study only cases where the fading is part of the transition from a stable arc (without significant rayed structures) to a local breakup. Furthermore, we selected only events where the fading occurred near the zenith of the camera. We have noticed that in the standard mode ASC recordings with 1 frame per min visual fading is not a very common phenomenon and a higher-resolu-

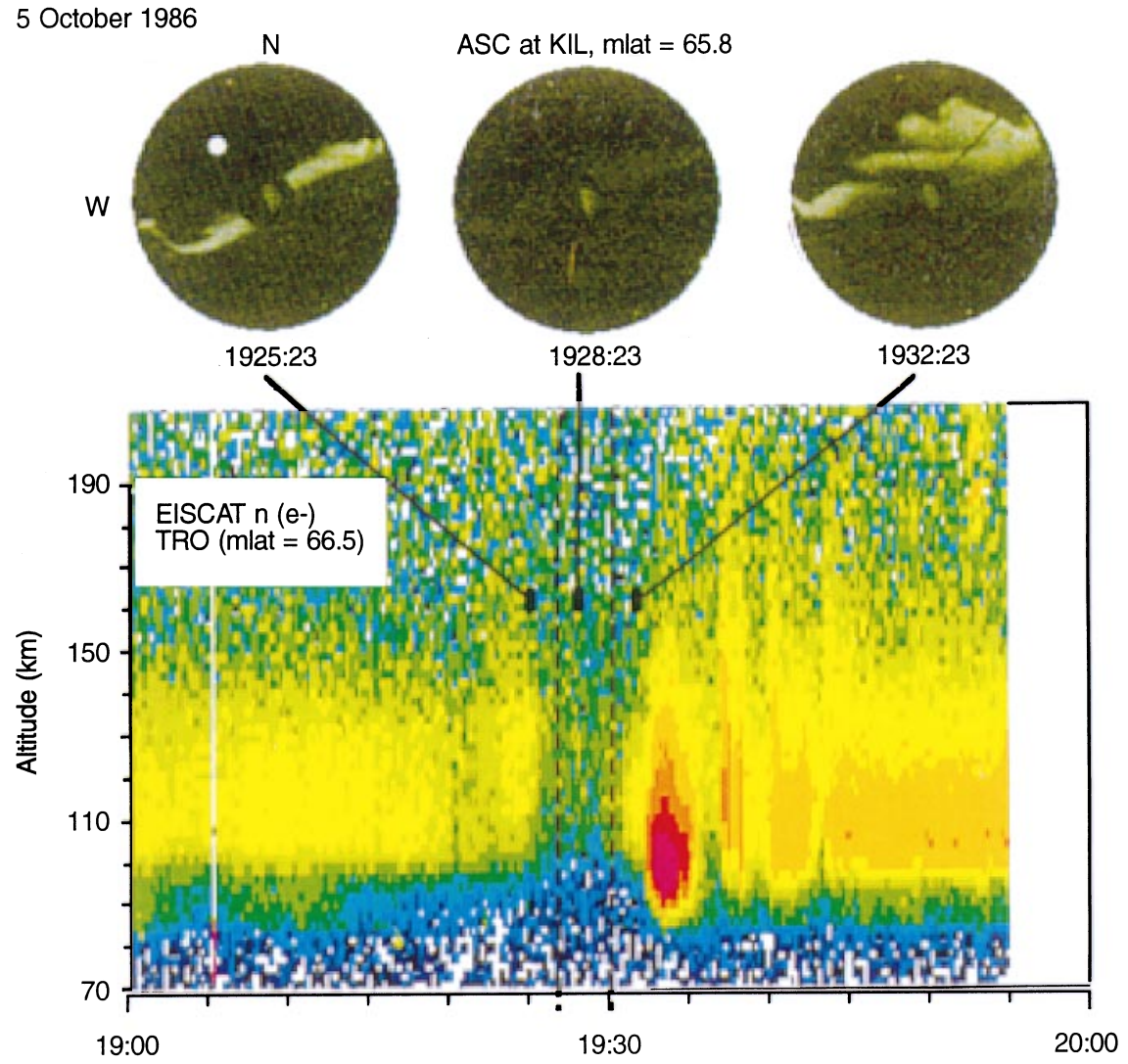

Fig. 1. Fading event on 5 October 1986: (upper panel) ASC frames recorded at KIL, and (lower panel) electron density recordings by the EISCAT radar at TRO (red, yellow, and green correspond to electron densities $10^{12}, 2.5 \cdot 10^{11}$, and $6.3 \cdot 10^{10} \mathrm{~m}^{-3}$, respectively). The approximate location of the fieldaligned radar beam is marked with the white dot in the first ASC frame 


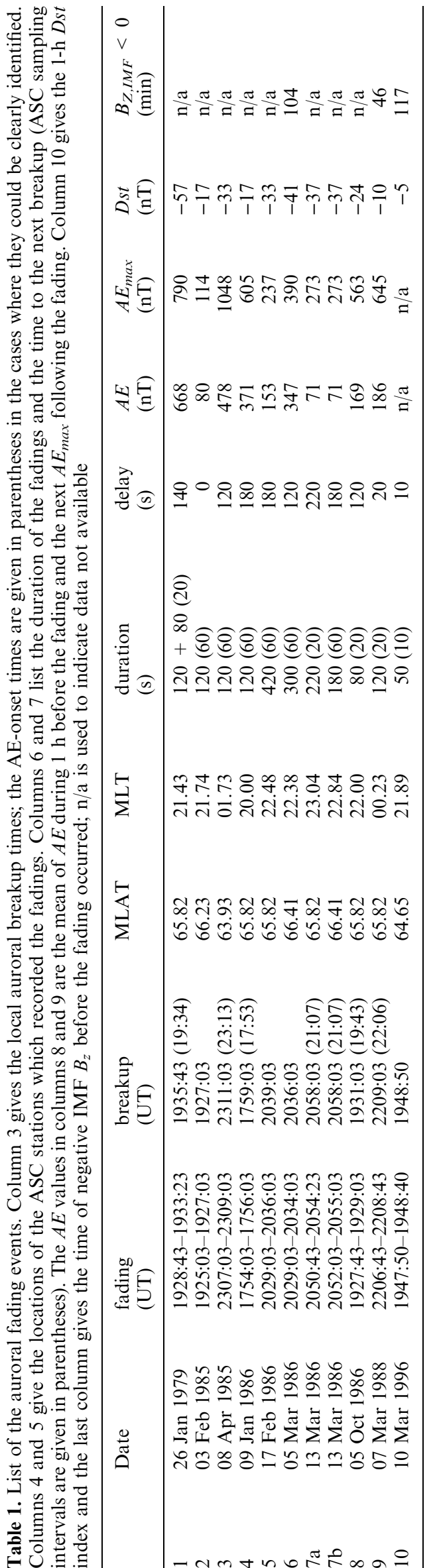

tion instrument would probably detect more events. This means that due to the strict selection criteria and instrumental limitations the ratio of the number of the events analyzed here to the number of all examined breakups is not a realistic estimate of the occurrence probability of the visual fading.

In Table 1 columns 2 and 3 show the fading and local breakup times, respectively. The start time of the fading is the time of the ASC frame where an arc starts to fade, and the end time is that of the frame where the arc is again visible. The auroral breakup is defined as the first active brightening of the $\operatorname{arc}(\mathrm{s})$ which is later followed by poleward expansion, rayed structures, or westwardtravelling surge. Note that the breakup time given is not always necessarily the time of the global onset. As a proxy for the global onset time, we give the onset time (if clearly identifiable) defined from the $A E$ index in parentheses in column 3 . In columns 4 and 5 are the magnetic latitude and local time [in the PACE coordinates by Baker and Wing (1989)] of the ASC stations where the fading was recorded. Column 6 lists the durations of the fadings (in seconds) and column 7 the delays to the next breakup. The delay of $0 \mathrm{~s}$ means that the fading was immediately followed by a breakup (not by a stable arc) in the ASC recordings. The values in columns 6 and 7 naturally depend on the time resolution of the ASC recordings which is given in parentheses in the sixth column. During event 1 two subsequent fadings took place and event 7 could be seen at two ASC stations. The details of the four last columns of Table 1 are explained in Sect. 4. The geographic locations of the ground-based stations used in the case-studies are listed in Table 2.

In most of the cases the local magnetic variations during and before the fading events could be studied with the data from the EISCAT Magnetometer Cross (Lühr et al., 1984), and a more global view on the magnetic activity level was achieved by inspecting the $A E$ and $D s t$ indices. The wide energy range of the fading effects reported earlier in event 8 (Kauristie et al., 1995) was verified in other cases with data from the EISCAT radar and riometers (Ranta et al., 1981). Interplanetary magnetic field data (from IMP-8) and electron fluxes from the closest Los Alamos National Laboratory (LANL) geostationary instrument were always checked when available. Particle and field recordings from GEOS 2 and AMPTE/IRM satellites were studied in events 1 and 3 , respectively.

\section{Case-studies}

\subsection{Observations: 26 January 1979}

The afternoon and evening of 26 January 1979 were magnetically very active, as shown by the $A E$ index in Fig. 2. After 1500 UT $A E$ stayed mainly above $400 \mathrm{nT}$ and showed onset-like enhancements so frequently that making any distinction between individual substorms is impossible. IMP-8 recorded negative IMF $B_{z}$ continuously during $\sim 1900-2335$ UT despite the unfortunate 
Table 2. Geographic locations of the ground-based stations mentioned in the text

\begin{tabular}{lllll}
\hline Name & abbreviation & geogr. lat. ${ }^{\circ} \mathrm{N}$ & geogr. lon. ${ }^{\circ} \mathrm{E}$ & instrument \\
\hline Kiruna & KIR & 67.8 & 20.4 & ASC, magnetometer \\
Kilpisjärvi & KIL & 69.1 & 20.8 & ASC, magnetometer \\
Sodankylä & SOD & 67.4 & 26.7 & ASC, magnetometer \\
Tromsø & TRO & 69.6 & 19.2 & EISCAT radar \\
\hline
\end{tabular}
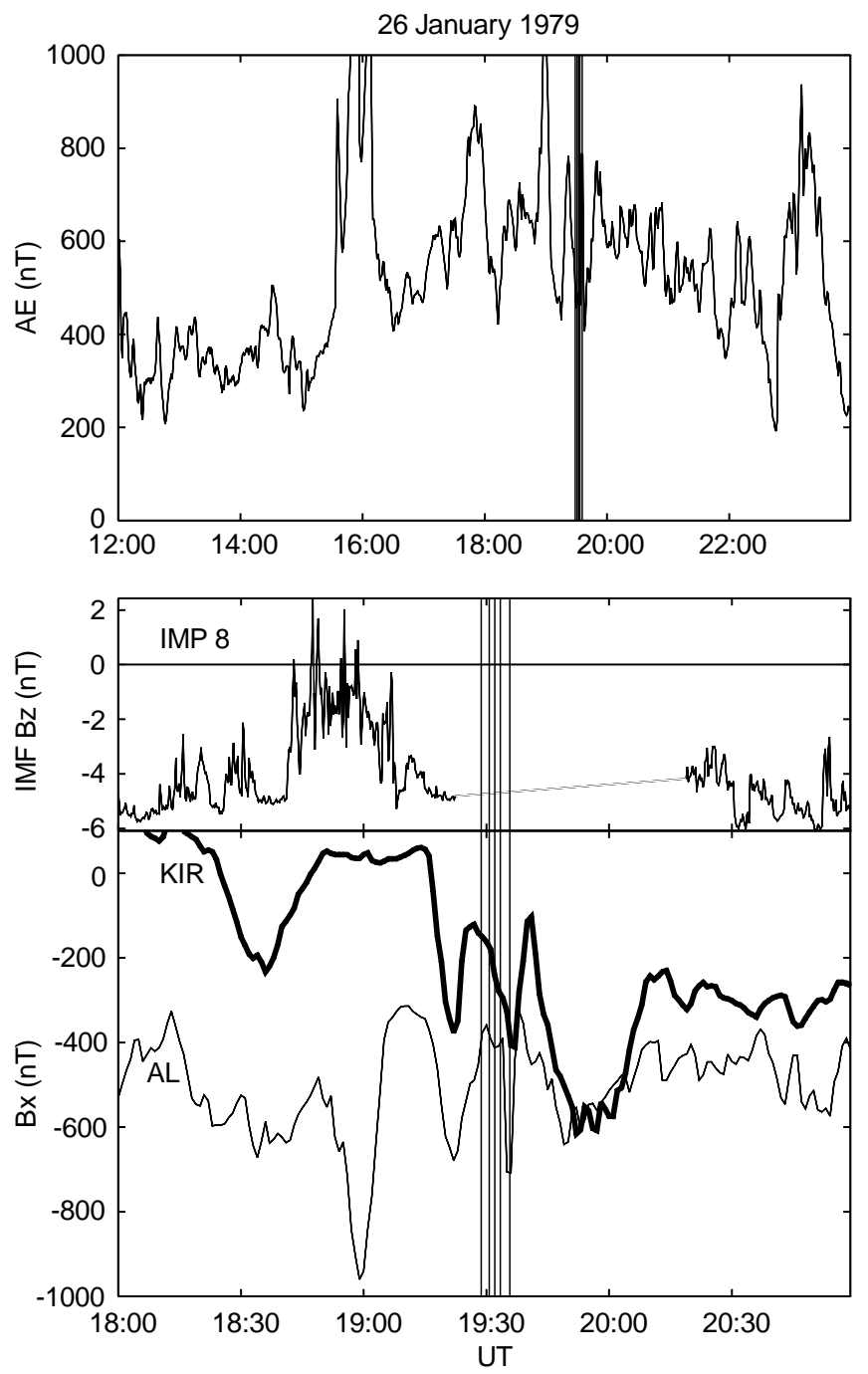

Fig. 2. Fading event on 26 January 1979: (top panel) $A E$ index before and after the fading times, (middle panel) IMF $B_{z}$ in GSM coordinates recorded by IMP-8 (satellite location: $X_{G S M}$ from 4.2 to $5.9 R_{E}, Y_{G S M}$ from -38.2 to $-37.7 R_{E}$, and $Z_{G S M}$ from 3.9 to $-1.8 R_{E}$ ), and (bottom panel) $\mathrm{AL}$ index (thin line) together with the local $B_{x}$ magnetogram at KIR (heavy line). The vertical lines mark the fading and breakup times

data gap at 1922-2020 UT (Fig. 2). Two subsequent fadings were recorded by the ASC at KIL at 1928 1933 UT, just before a very sharp negative peak in $B_{x}$ recordings at KIR. The peak is also visible in the $A E$ index and it is followed by a longer intensification starting at $\sim 1938$ UT (Fig. 2).

Remnants of the previous activity (c.f. Fig. 2, the magnetic activation around 1920 UT) were still visible in the southern part of the ASC frame recorded at KIL at 1925:03 UT when a new arc near the zenith showed up (from east to west). Frame 1 of Fig. 3 (left panel) shows this arc (at 1927:03) which drifted southward between 1928:43 and 1930:23 UT. The western part of the arc faded (frame 2). During 1930:43-1931:43 UT the entire dim arc was visible (frame 3 ) but it faded again during 1932:03-1933:03 UT (frame 4). The arc returned at 1933:23 UT and brightened slightly at 1934:03, just before the breakup at 1935:43 UT (frames 5 and 6). The last brightening, as well as the breakup, came into the field of view of the ASC from the eastern horizon, suggesting that the global onset took place somewhere closer to local midnight (MLT at KIL was 21.43).

The magnetic field data recorded by GEOS 2 around the two fading periods are shown as solid curves in the first three panels of Fig. 4. The substorm around 1920 UT was recorded by GEOS 2 as a strong field dipolarization around $1918 \mathrm{UT}$. After $1924 \mathrm{UT} B_{z}$ started to decrease rapidly, by $\sim 30 \mathrm{nT}$ in only $\sim 10$ min. During that time $B_{y}$ increased gradually and $B_{x}$ showed variable behavior. At GEOS 2 the following dipolarization took place at 1935 UT. The ASC at KIL recorded the breakup $\sim 40 \mathrm{~s}$ later (frame 6 at 1935:40 UT). In Fig. 4 the time of ASC breakup is marked by the vertical solid line and the fading periods by the gray shading. The clearest increases in $B_{y}$ took place around the fading periods, but otherwise no clear systematic changes in the general growth phase trend are visible in the GEOS 2 B recordings during the fading periods, or immediately before the fading periods.

The last two panels of Fig. 4 show $E_{x}$ and $E_{y}$ (in GSM-coordinates, solid line) recorded by GEOS 2 . Around the fading periods the magnetic and electric field showed fewer rapid variations than during the rest of the observing period.

GEOS 2 recorded differential electron and ion fluxes in 14 energy channels $(16-213 \mathrm{keV})$ and in 19 different pitch angle (PA) ranges $\left(0-5^{\circ}, 5-15^{\circ}, \ldots, 175-180^{\circ}\right)$. The complete range of $180^{\circ}$ was scanned in $55 \mathrm{~s}$. Electron fluxes in the PA ranges $0-25^{\circ}$ and $65-95^{\circ}$ are presented in Fig. 5. The electron fluxes with $65-95^{\circ}$ PAs already started to decrease a couple of minutes before the beginning of growth phase in $B_{z}(\sim 1924 \mathrm{UT})$. In the period 1924-1927 UT the perpendicular fluxes continued to decrease, while the field-aligned fluxes stayed at the same level or even increased somewhat. Around 1927 UT, however, the behavior changed clearly, especially in energy levels $37.5-70.5 \mathrm{keV}$. Then the perpendicular electron fluxes started to decrease more rapidly and even the field-aligned fluxes started to drop. Around 1934 UT all electron fluxes started to increase, showing typical onset injection behavior. The ion fluxes (data not 

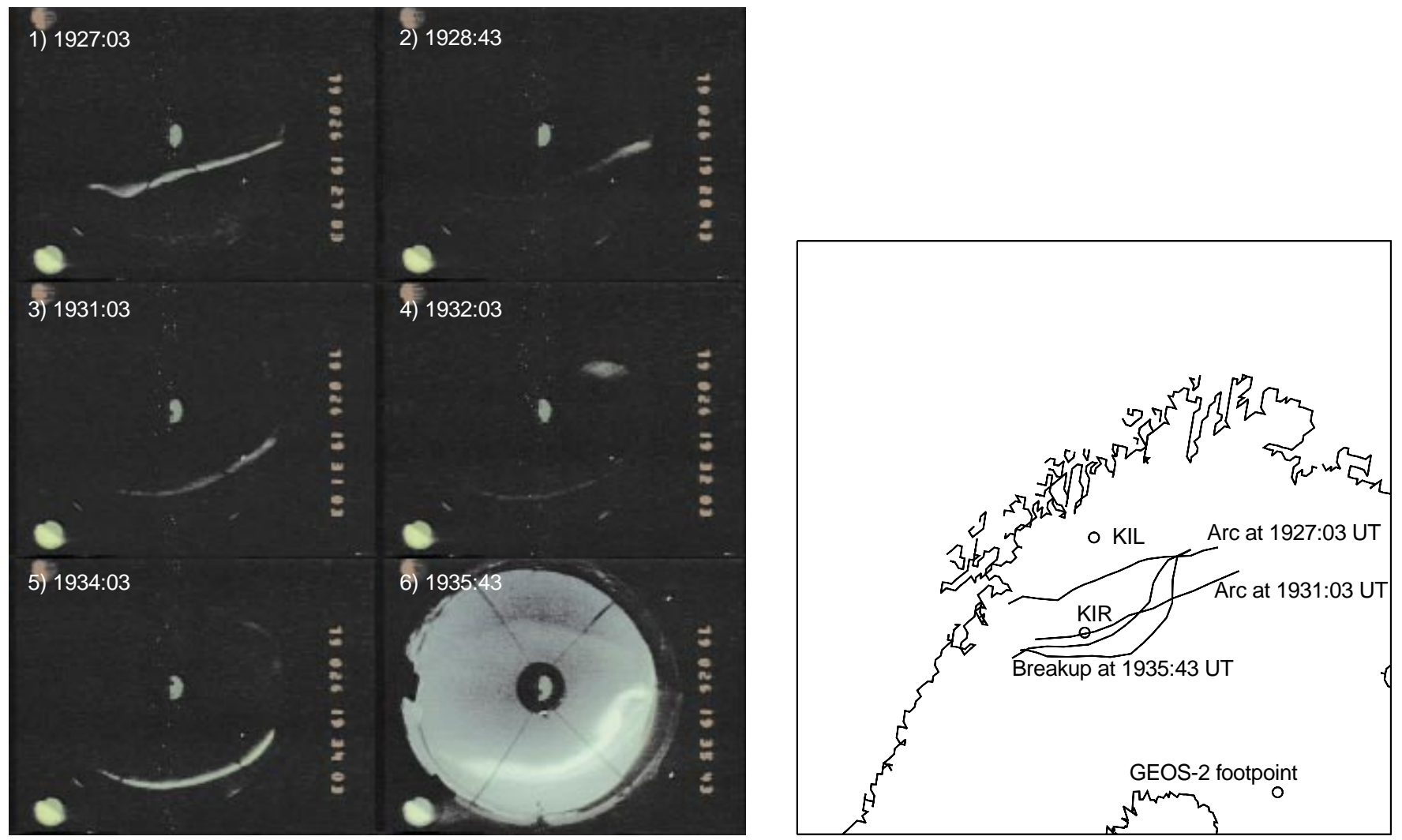

Fig. 3. Fading event on 26 January 1979: (left) Six ASC frames from KIL, and (right) the approximate locations of the auroral arc on the map of northern Scandinavia (The jagged line is the Norwegian-Russian coast line) at two times before the fadings and at the time of the breakup

shown here) had some variations during the growth phase, but not such clear trends as the electron data. No immediate onset injection effects were recorded in the ion fluxes either. As electrons drift eastward from the onset region we can conclude that the onset took place to the west of GEOS 2 (and to the east of the groundbased observation points).

\subsection{Data analysis: 26 January 1979}

In the right panel of Fig. 3 the arcs from frames 1, 3, and 6 are shown on a map together with the footpoint of the GEOS 2 satellite. At that time the satellite location was $X_{G S M} \sim-5.2 R_{E}, \quad Y_{G S M} \sim 3.9 R_{E}$ and $Z_{G S M} \sim-1.3 R_{E}$. The footpoint has been defined with a time-evolving magnetic field model by Pulkkinen et al. (1991). The model was adjusted to GEOS 2 observations of the magnetospheric magnetic field by varying a few timedependent parameters controlling the cross-tail current systems in the standard Tsyganenko magnetic field model (Tsyganenko, 1989, hereafter T89). Using this method the GEOS 2 footpoint turned out to be located about $2^{\circ}$ to the south of the southernmost arc in Fig. 3 and about $7^{\circ}$ to the west from the zenith of KIL. Thus according to the model field mapping the arc and the breakup originated at distances beyond the geostationary orbit.
As the satellite footpoint latitude is mainly determined from the amount of magnetic flux crossing the equatorial plane (i.e., the $B_{z}$ component), we adjusted the model parameters to get a best fit for that component (c.f., Fig. 4). Inaccuracies in $B_{x}$ and $B_{y}$ probably indicate the presence of field-aligned currents or asymmetries in the field not included in the model. In particular, due to the differences in $B_{y}$ the real footpoint of GEOS 2 may be somewhat westward from the point shown in Fig. 3.

The dashed lines in the three first panels of Fig. 4 show B according to the T89 model $\left(K_{p}=3\right)$. Although $K_{p}$ was $4+$ during the studied period, the model for $K_{p}=3$ fits the GEOS 2 recordings best. The T89 model $\left(K_{p}=3\right)$ has been used as the starting point for the timeevolving magnetic field model. The trends achieved with the model are shown with the solid lines in Fig. 4. The results suggest that the $B_{z}$ decrease during $\sim 1924-1935$ UT was caused by a growing cross-tail current system, which developed tailward of geostationary orbit. The center of the enhancing current system was at $\sim 8 R_{E}$ and its intensity was $\sim 1.5$ times the T89 $\left(K_{p}=3\right)$ ring-current intensity [see Pulkkinen et al. (1992) for model details]. From these data alone it is not possible to deduce whether a thin current sheet developed further tailward; the effects of the probable current-sheet thinning to the field at the satellite location would have been small. The $B_{x}$ deviations toward more 
26 January 1979 GEOS 2

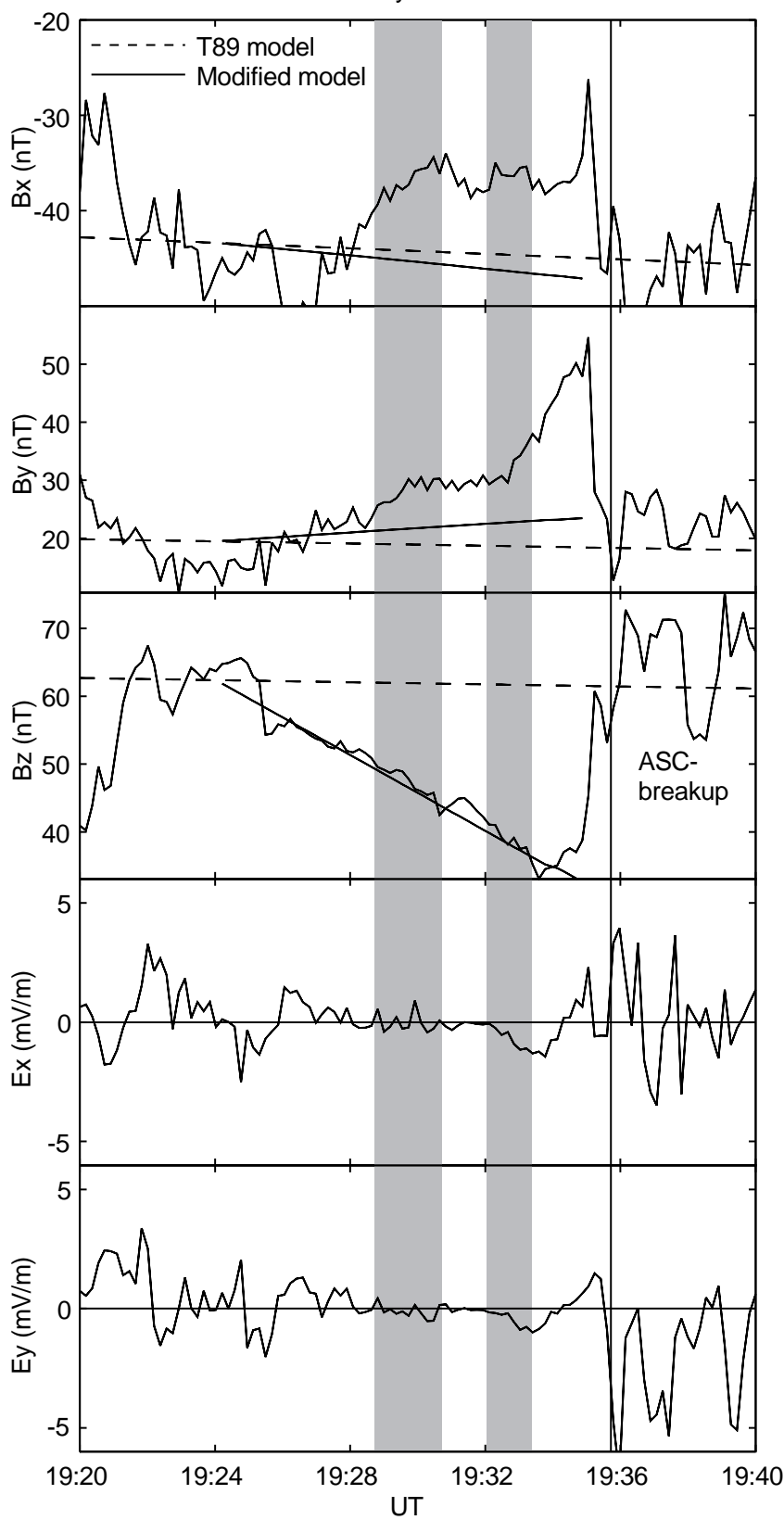

Fig. 4. Field recordins (in GSM coordinates) by GEOS 2 (satellite location: $X_{G S M}$ from -5.0 to $-5.4 R_{E}, Y_{G S M}$ from 4.1 to $3.6 R_{E}$, and $Z_{G S M}$ from -1.2 to $-1.4 R_{E}$ ) around the auroral fadings on 26 January 1979: (from top to bottom) $B_{x}, B_{y}, B_{z}, E_{x}$, and $E_{y}$. The gray shadings show the fading times and the vertical solid line marks the time of the auroral breakup. In the three first panels the time trends marked with the dashed and solid lines are the field values according to T89 and the modified magnetic field model, respectively.

positive values than the model suggests are consistent, e.g., with field-aligned currents away from the ionosphere and located to the west of the satellite (which was below the equatorial plane). Furthermore the increases in $B_{y}$ suggest that the currents extended tailward of the satellite location.

The electric field recordings of GEOS 2 were local and thus do not represent large-scale electric field. However, the data shown in Fig. 4 suggest that neither
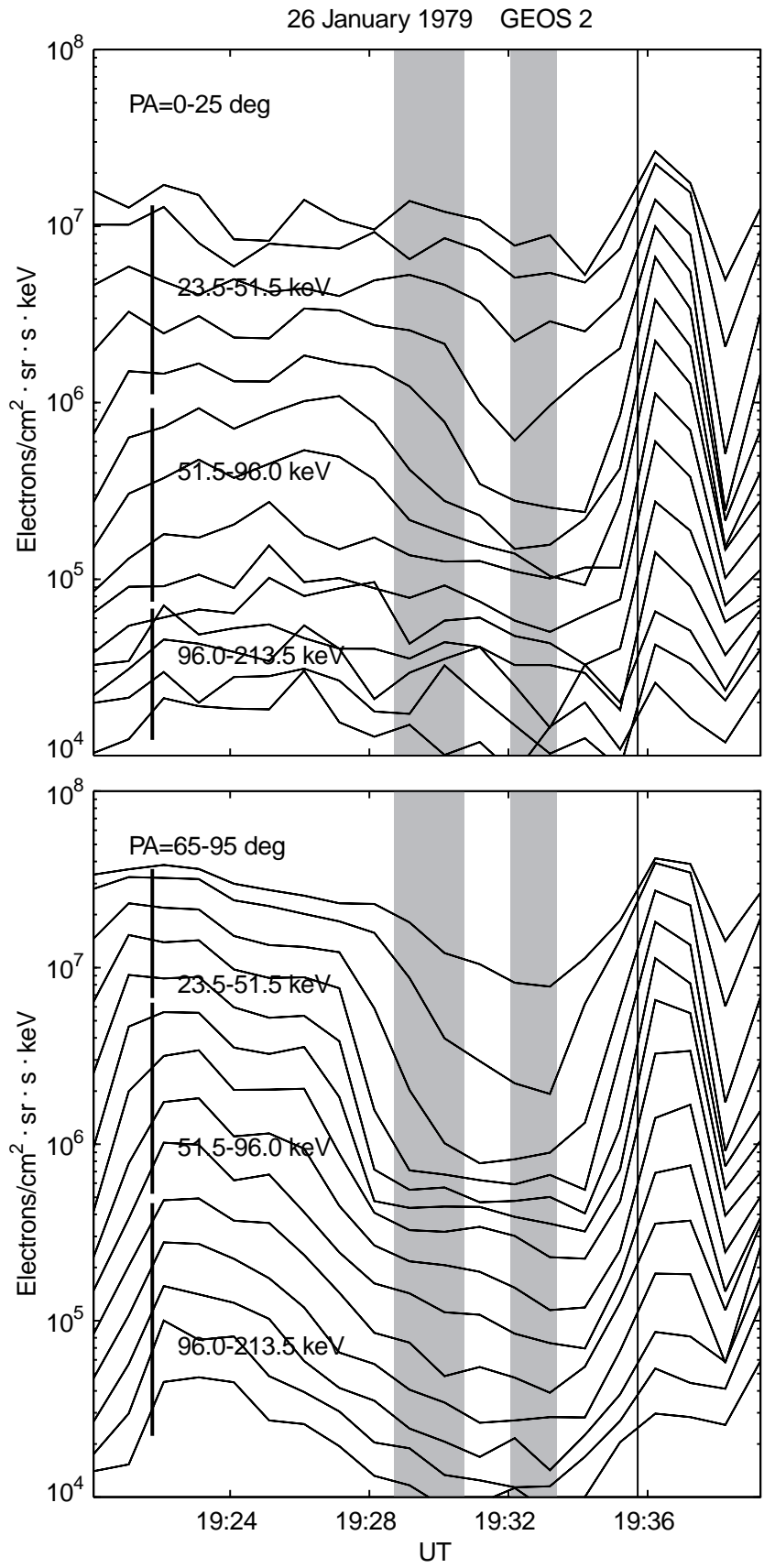

Fig. 5. Differential electron flux recordings by GEOS 2 (for satellite location see the previous figure caption) around the auroral fadings on 26 January 1979: (upper panel) electrons with pitch angles $0-25^{\circ}$, and (lower panel) and with pitch angles $65-95^{\circ}$. The gray shadings show the fading times, and the thin vertical solid line marks the time of the auroral breakup. The energy channels are (from top to bottom): 16-23.5, 23.5-30, 30-37.5, 37.5-44.5, 44.5-51.5, 51.5-60.5, 60.5-70.5, 70.5-83, 83-96, 96-113.5, 113.5-133, 133-153.5, 153.5-180, and 180 $213.5 \mathrm{keV}$

small-scale turbulence nor strong inductive electric field were present at geostationary orbit during the fading periods.

The decreases in the perpendicular electron fluxes recorded by GEOS 2 are consistent with the previous observations by Baker et al. (1978). They found 
systematic cigar-type electron distributions (i.e., higher fluxes around $\mathrm{PA}=0^{\circ}$ and lower around $\mathrm{PA}=90^{\circ}$ ) at all energy levels $\geq 30 \mathrm{keV}$ during the growth-phase magnetic field stretching. In the stretched magnetic field drift-shell splitting which guides particles with large PAs closer to the Earth can account for the flux decreases in PA $\sim 90^{\circ}$ particles: then a geostationary satellite monitors $\mathrm{PA} \sim 90^{\circ}$ particles which were previously somewhat further down the tail, where the fluxes of energetic particles are lower.

Whether GEOS 2 recorded cigar-type distributions can be checked in first approximation by studying the ratio of $0-25^{\circ} \mathrm{PA}$ fluxes to $65-95^{\circ} \mathrm{PA}$ fluxes $\left(r_{P A}\right) ; r_{P A}$ suggests that during $\sim 1920-1928 \mathrm{UT}$, after the previous onset, the electron distributions were still of pancake type (i.e., higher fluxes around $\mathrm{PA}=90^{\circ}$ and lower around $\left.\mathrm{PA}=0^{\circ}, r_{P A}<1\right)$. During 1928-1934 UT cigartype distributions $\left(r_{P A}>1\right)$ were recorded at the energy
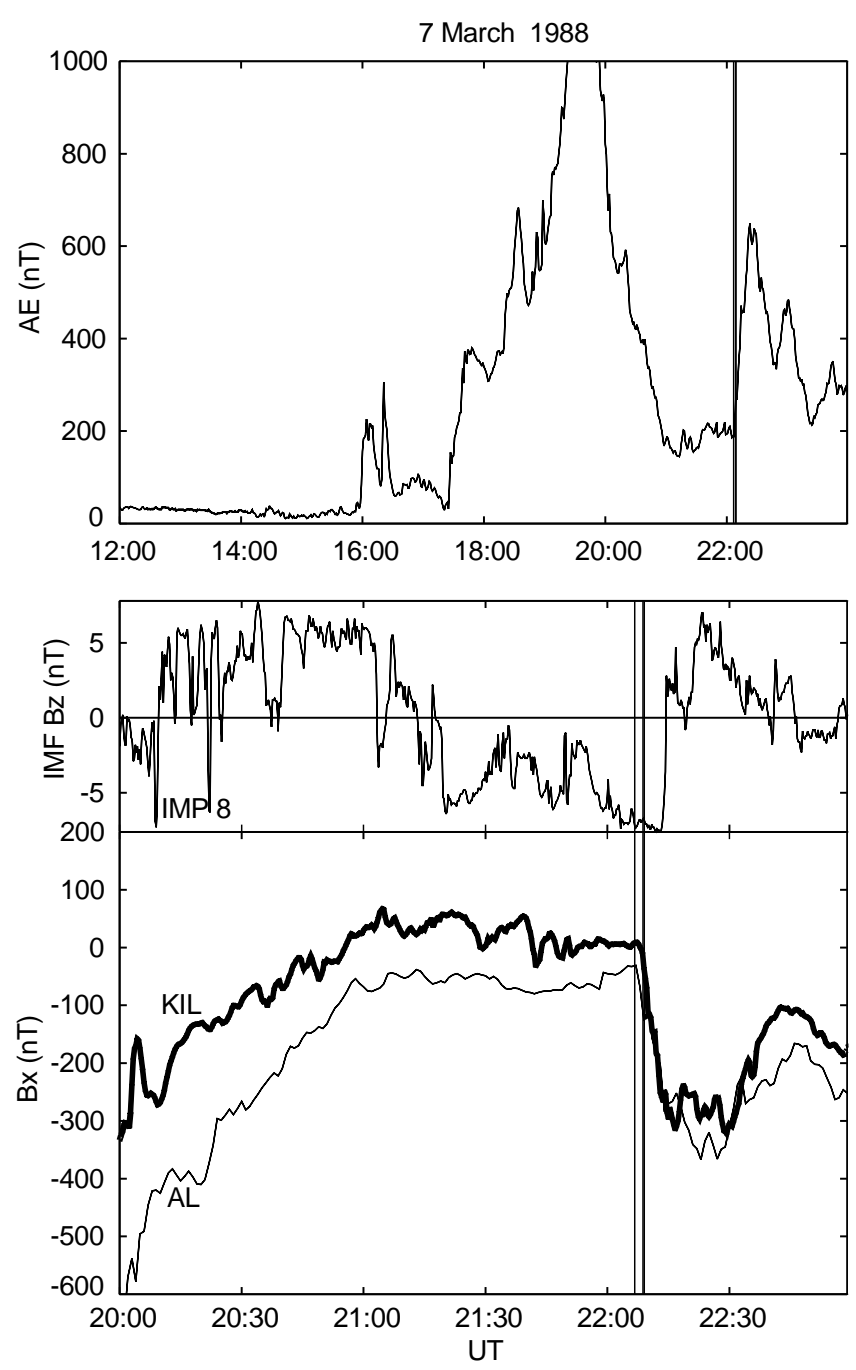

Fig. 6. Fading event on 7 March 1988: (top panel) $A E$ index, (middle panel) IMF $B_{z}$ in GSM coordinates recorded by IMP-8 (satellite location: $X_{G S M}$ from 17.8 to $15.9 R_{E}, Y_{G S M}$ from 27.2 to $28.4 R_{E}$, and $Z_{G S M}$ from 2.2 to $3.9 R_{E}$ ), and (bottom panel) $\mathrm{AL}$ index (thin line) together with the local $B_{x}$ magnetogram from KIL (heavy line). The vertical lines mark the fading and breakup times ranges $23.5-51.5 \mathrm{keV}$ and $96-213.5 \mathrm{keV}$. In the range $51.5-96 \mathrm{keV}$, however, $r_{P A}$ exceeded 1 only occasionally. Evidently this is partly due to the decrease in the 0 $25^{\circ}$ PA fluxes after 1927 UT in these energy channels. This decrease is not consistent with drift shell splitting and cannot be explained by thinning of the plasma sheet either (as the effect was recorded only in a limited energy range and as according to the magnetic field model GEOS 2 was located close to the magnetic equator).

\subsection{Observations: 7 March 1988}

The latter portion (after 1600 UT) of 7 March 1988 was magnetically active. In Fig. 6, $A E$ shows three distinct substorms $(\sim 1600, \sim 1730$, and $\sim 2200$ UT $)$. The third substorm, which we discuss here, started when $A E$ was still disturbed by the previous activity. IMP-8 recorded negative interplanetary magnetic field (IMF) $B_{z}$ values during $\sim 2120-2210$ UT (Fig. 6). The magnetometer at KIL recorded negative $B_{x}$ deviations during 1800-2100 and 2200-2400 UT. During 2200-2400 UT KIL was close to the most active region (MLT $\sim 0.3-2.3$ ) as the $B_{x}$ deviations recorded there were of the same order of magnitude as the simultaneous $A L$ index (Fig. 6).

During 2150-2204 UT the ASC at KIL recorded auroral activity in the southern horizon together with a few arcs in the northern sky. In the frames 2204:232206:03 UT a narrow arc built up near the zenith (frames 1 and 2 of Fig. 7). During 2206:43-2208:23 UT this arc faded especially in its eastern part (frames 3 and 4). At $2208: 43$ UT the auroral activity in the eastern sky brightened (frame 5) and the arc near zenith returned. The next frame at 2209:03 UT shows a breakup which probably propagated from the eastern activity to the arc which had faded earlier.

Around 2200 UT the beam of the EISCAT radar was directed toward KIL with a southeast azimuth and an elevation angle of $40^{\circ}$. Figure 7 shows the electron densities recorded at four points along the beam. The points were at altitudes $100,106,112$, and $117 \mathrm{~km}$ and formed a chain (horizontal range $\sim 20 \mathrm{~km}$ ) pointing toward the southeast, located just south of the zenith of KIL (marked with the white line in frame 2). The electron densities recorded at the two southernmost points (curves 1 and 2 in the right panel of Fig. 7) show a peak between 2205 and 2206 UT which is related to the narrow arc in the second ASC frame in Fig. 7. The peak is missing from the two other density curves because the arc did not drift from north to the zenith of KIL but rather brightened from east to west. All density curves show a drop around the fading time, but the densities at the two northernmost points (curves 3 and 4) started to decrease a few minutes earlier than at the two southernmost points.

Figure 8 (left panel) shows differential electron fluxes (energies $30-300 \mathrm{keV}$ ) recorded by the LANL instrument (onboard satellite 1984-037) around the fading time. The satellite was located in the morning sector about 3 MLT-hours ahead of the ground-based stations. The electron detector started to record gradually 

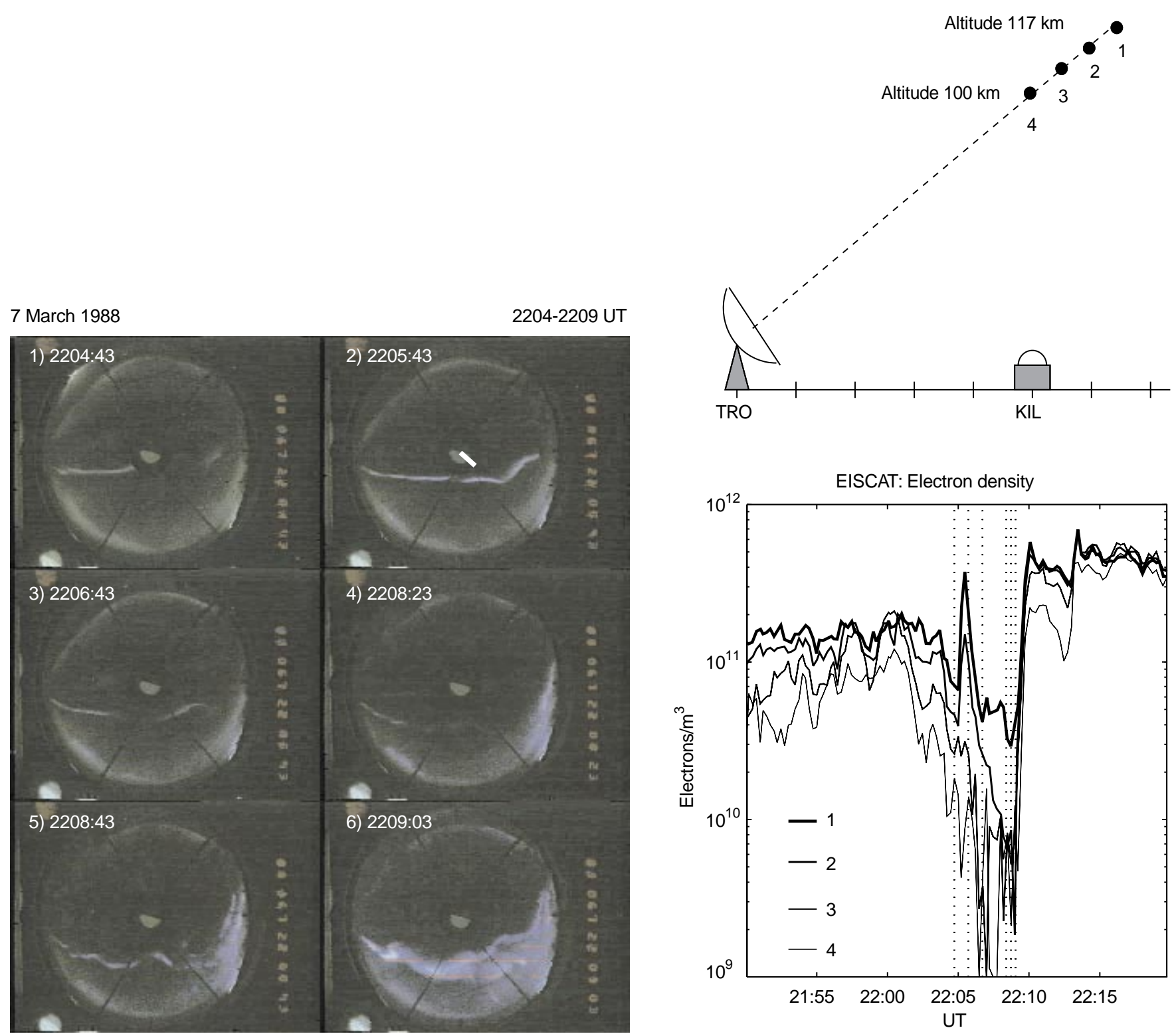

Fig. 7. Fading event on 7 March 1988: (left) six ASC frames from KIL, and (right) electron density recordings by the EISCAT radar at TRO. In the upper right panel the locations of the measuring points are marked with the same numbers as used for labelling the curves in the

decreasing fluxes at 2130 UT. At the time of the fading the fluxes had a transient drop after which they started to fluctuate rapidly. A more stable increase in the fluxes started $\sim 20$ min after the fading observation.

\subsection{Data analysis: 7 March 1988}

During the fading event on 5 October 1986 (Fig. 1), the field-aligned recordings of the EISCAT radar did not show any significant altitude dependence in the electron densities in the altitude range $100-120 \mathrm{~km}$. If we assume the same behavior also here, the curves of Fig. 7 can be used for estimating the latitudinal development of the fading. In this case the fading propagated from north to lower right panel. The vertical dotted lines mark the times of the ASC frames. The approximate locations of the measuring points are shown with the white line in the ASC frame (2)

south as the densities at the two northernmost points started to decrease earlier than at the two southernmost points. In addition, the relative density decrease in the northern dark region is of the same order or even larger than in the vicinity of the visible arc. These observations are consistent with the previously analyzed fading events where the northern sky darkened before and during the fading (Pellinen and Heikkila, 1978).

The transient drop recorded by the LANL instrument in the differential electron fluxes at the time of the fading was deeper in the higher-energy channels $(\geq 65 \mathrm{keV})$ and showed clear time dispersion. Both these features are typical of drifting electron holes (DEH), which according to Sergeev et al. (1992), see also Shuktina et al. (1996), are signatures of onset injection, 


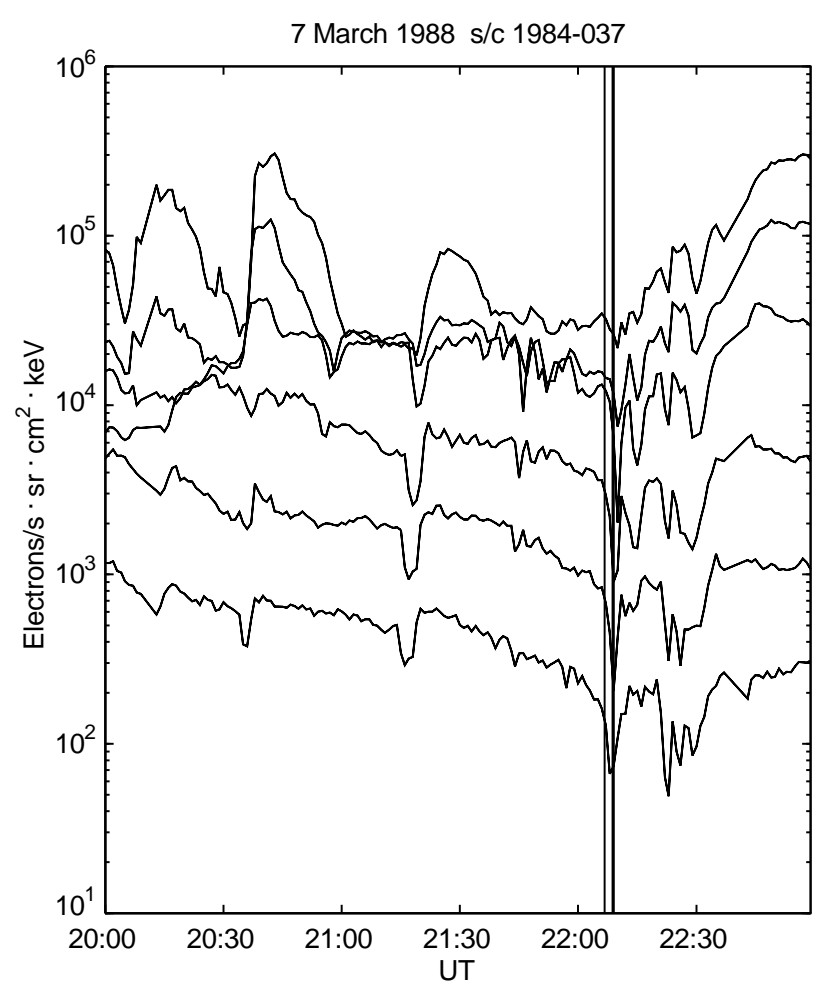

Fig. 8. Global conditions around the fading event on 7 March 1988. The left panel: differential electron fluxes recorded by the geostationary satellite 1984-037. The vertical lines mark the fading and breakup times, and the energy channels are (from top to bottom) 30-45, 45-65, 65-95, 95-140, 140-200, and 200-300 keV. The right panel: a pass of DMSP F9 satellite (in MLT-MLAT coordinates) together with

similar to the more typical abrupt flux increases in the lower-energy channels. Consequently, the flux fluctuations which started at the time of the fading signal the formation of the substorm current wedge to the west of the satellite and subsequent expansion to the satellite location. Thus in this case the global onset had already started at the time when the fading was observed.

The location of the fading arc (frame 2 in Fig. 7) with respect to the larger-scale morphology of the auroral precipitation is shown in Fig. 8 (right panel). The nightside precipitation can be divided roughly into two categories: the CPS-precipitation has smooth spatial and spectral structure and consists of particles with energies of several $\mathrm{keV}$ or tens of $\mathrm{keV}$ (ions). BPS precipitation is usually poleward of the CPS regime, has fewer highenergy ions and more low-energy electrons, and its spectrum is more structured (Newell et al., 1991). The discrete arcs lie typically within the BPS regime; the CPS regime is often related to the diffuse oval. The magnetospheric origin of the low-altitude CPS and BPS regimes have been widely discussed; according to a quite generally accepted view CPS maps to the inner edge of the plasma sheet and BPS to the central plasma sheet (Galperin and Feldstein, 1991).

The Defence Meteorological Satellite Program (DMSP) satellites monitor the low-altitude $(\sim 800-\mathrm{km})$ precipitation along tracks either from dawn to dusk or from prenoon to premidnight. On 7 March 1988 the

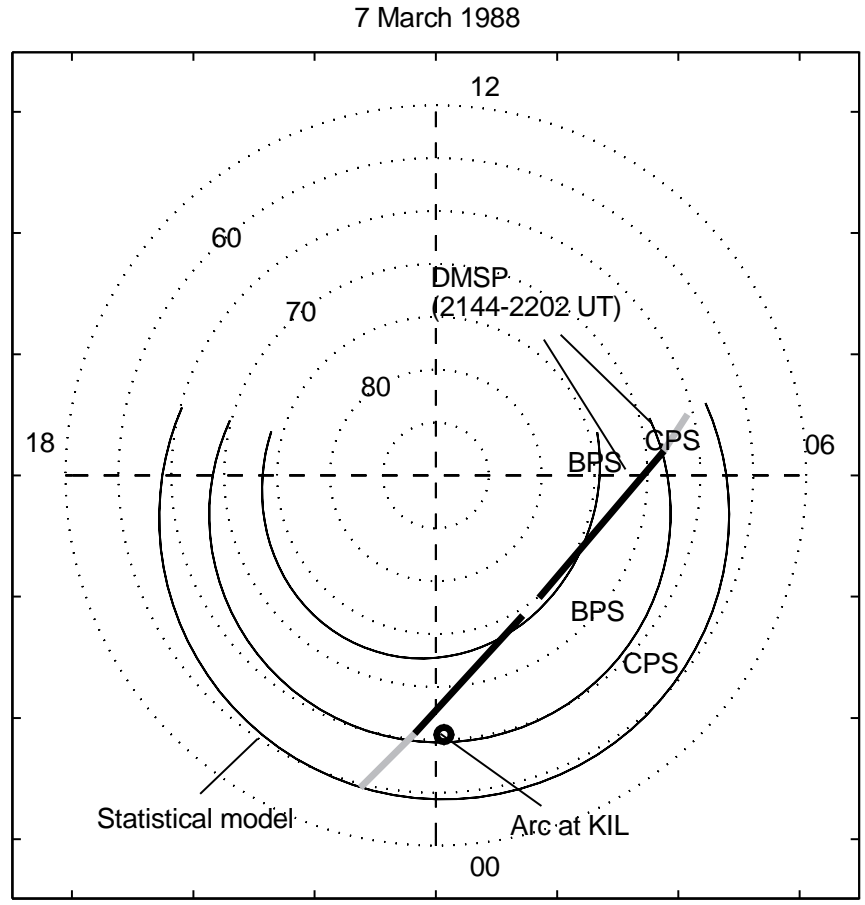

statistical models for the CPS and BPS precipitation regimes (for more details, see text). The gray and black heavy solid lines show the CPS and BPS regimes, respectively, as recorded by DMSP F9 (2144 2202 UT), and the thin solid lines show the statistical boundaries. The location of the fading arc at KIL is marked with a circle

DMSP F9 track during 2143:52-2201:58 UT was closest to the fading observation. Figure 8 (right panel) shows the CPS and BPS regimes along this track as defined by a neural network system (Newell et al., 1991). The BPS/ CPS boundary at magnetic midnight was recorded at 2155:54 UT, i.e., about $10 \mathrm{~min}$ before the fading. Together with the instantaneous DMSP recordings, statistical models (Kauristie, 1995) for the BPS and CPS boundaries are shown. When developing the models, the boundary locations defined by the automated system of Newell et al. (1991) were binned according to the $A E_{\max }$ during the preceding $2 \mathrm{~h}$ and according to the substorm phase (defined from $A E$ ). Here we show the expansion phase models of the activity level $700 \mathrm{nT}<A E_{\max } \leq 1000 \mathrm{nT}$, which best describe the disturbance level before and during the DMSP recordings. Both the DMSP recordings and the statistical models suggest that the fading arc was within the BPS oval, but very close to the CPS/BPS transition boundary. Thus the origin region of the fading arc was clearly closer to the inner edge of the plasma sheet than to the far-tail reconnection line.

\subsection{Observations: 10 March 1996}

As $A E$ data of 10 March 1996 is not yet available, we estimate the global activity level with a local $A E$ index 
$\left(A E_{l o c}\right)$ (Kauristie et al., 1996), which in this case is based on the data of the IMAGE magnetometer chain (Lühr, 1994). $A E_{\text {loc }}$ shows relatively strong activations (maxima around 400-600 nT) both before and after the fading events (Fig. 9). Also, satellite data reveal that the day was generally active with many injection events and several periods of southward IMF $\left(K_{p}=3\right.$ for the period 1800-2100 UT). Especially during $\sim 1750-1954$ UT IMF $B_{z}$ (1-min averages) stayed continuously negative at IMP-8 (Fig. 9). The $A E_{l o c}$ substorm after 1800 UT took place at high latitudes $\left(\sim\right.$ magn. lat. $\left.71^{\circ}\right)$, beyond the reach of the magnetometers at KIR and SOD. Between 1930 and 2030 UT these stations recorded four $B_{x}$ activations which repeated with increasing intensity (maximum $\left|\Delta B_{x}\right| \sim 300 \mathrm{nT}$ ) every $\sim 15$ min (Fig. 9).

In parallel to the ASC film at KIL, the auroral activity was recorded with a new CCD camera at KIR ( $\sim 100 \mathrm{~km}$ southwest of KIL). During 1928-2030 UT the digital camera recorded with a time resolution of $10 \mathrm{~s}$ and with 0.5 or 0.8 -s exposure times (the corresponding parameters for the ASC at KIL were 1-min resolution and 2-s exposure time). During 19111925 UT southward-drifting arcs were recorded in the northern sky at KIL. The intensity of the southernmost arc varied during 1926-1931 UT (three fadings) and at 1932 UT a small breakup (or pseudo-breakup) took place (the first activation in the magnetograms, auroral data not shown here). After activation the arc remained brightened and at approximately the same place.

Figure 10 shows ASC recordings at KIR and KIL before the next breakup at 1948:50 UT. The arc which remained after the pseudo-breakup is the bright arc in the ASC frames of KIR, which corresponds to the southernmost arc in the frames of KIL. During 1947:50 1948:30 UT the KIR ASC recorded a fading which propagated as a "dark zone" (with longitudinal extent of $\leq 1$ MLT-hour) from east to west along the arc. In the frame 1948:40 UT the dark region is followed by a bright horn also propagating from east to west. Both the fading and the bright horn were such transient phenomena that the ASC at KIL partly missed them due to the 1-min imaging interval. The breakup took place at $\sim 1949$ UT and started a large-scale substorm with further intensifications at $\sim 2000$ and $\sim 2011$ UT (the third and fourth activations in the magnetograms).

The LANL-instrument onboard the geostationary satellite 1991-080 was recording differential electron fluxes (Fig. 11) at the longitude 69.3, 3 MLT-hours to the east of the ground-based stations. At the time of the fadings before the first small breakup (dashed lines in Fig. 11), the fluxes at 1991-080 showed a transient sharp decrease which was followed by an increase in the three lowest energy channels $(\leq 150 \mathrm{keV})$. The fluxes returned back to the previous level after $\sim 10 \mathrm{~min}$. At the time of the second breakup (also preceeded by fading marked with the solid lines in Fig. 11) fluxes again increased in the low-energy channels (without transient decrease this time) and a small but clear decrease was recorded at the two highest energy channels.
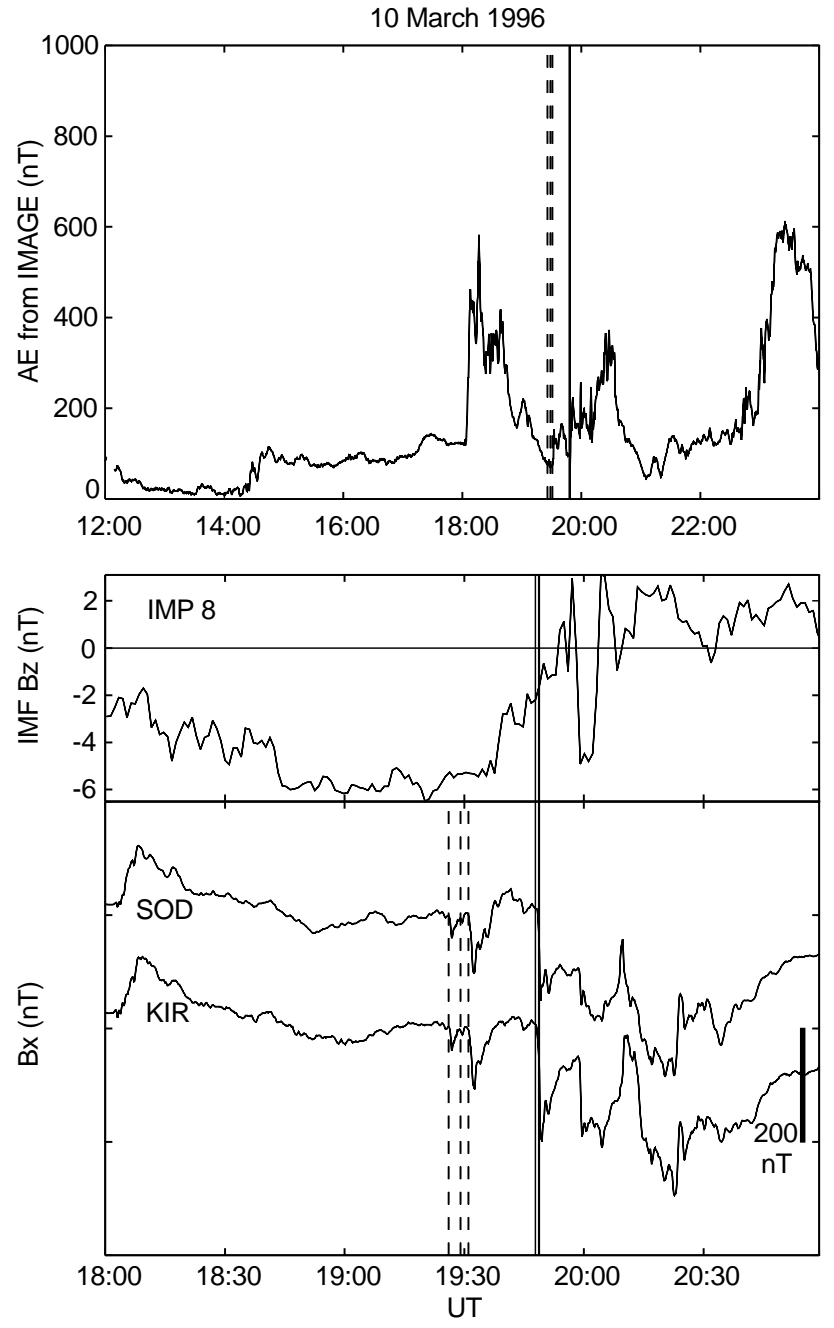

Fig. 9. Fading event on 10 March 1996: (top panel) local $A E$ index computed using data from the IMAGE magnetometer chain, (middle panel) IMF $B_{z}$ in GSM coordinates recorded by IMP-8 (satellite location: $X_{G S M}$ from 32.7 to $33.0 R_{E}, Y_{G S M}$ from -15.3 to $-15.6 R_{E}$, and $Z_{G S M}$ from 11.9 to $11.7 R_{E}$ ), and (bottom panel) $B_{x}$ magnetograms at SOD and KIR. The vertical lines mark the fading and breakup times. The fadings before the pseudo-breakup are marked with the dashed lines

\subsection{Data analysis: 10 March 1996}

At the time of the fadings before the first small breakup $(\sim 1932$ UT $)$, the fluxes recorded by the LANL instrument showed DEH-like signatures, suggesting that an injection had taken place before the fading observations. At the time of the second breakup ( 1949 UT), however, the signatures of the global onset (i.e., an increase in the low-energy fluxes and DEHs in the highenergy fluxes) are visible later at 1991-080 than at KIL. Thus in this case it is possible that the local breakup recorded at KIL and KIR was close (both spatially and temporally) to the second global onset and that the fading at 1947:50-1948:40 UT took place before the onset. 
10 March 1996 1947-1949 UT

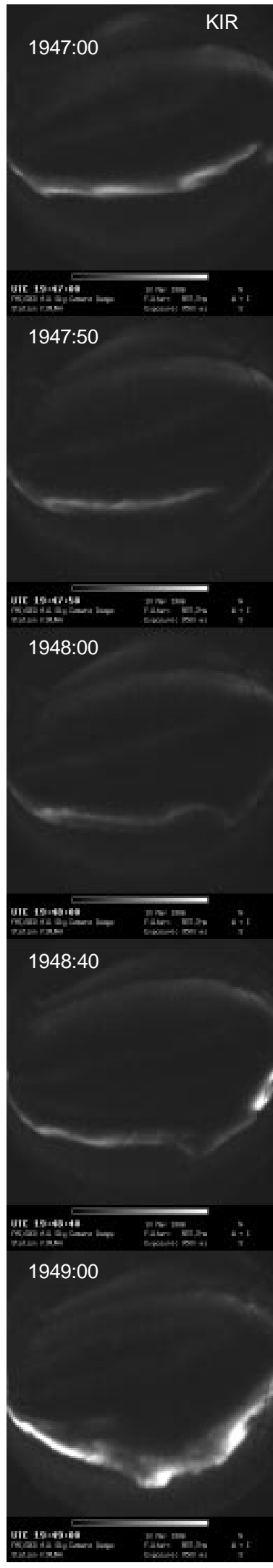

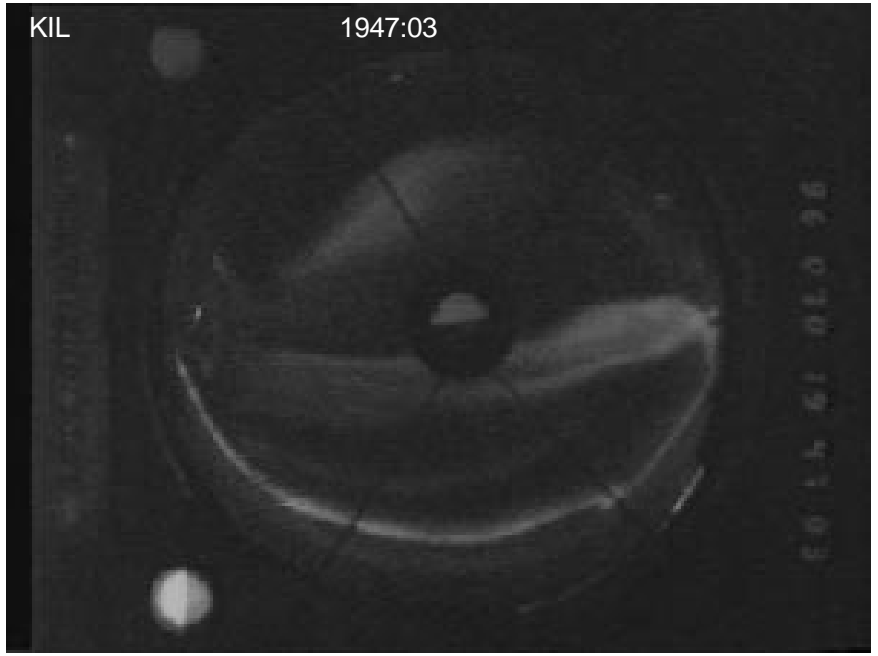

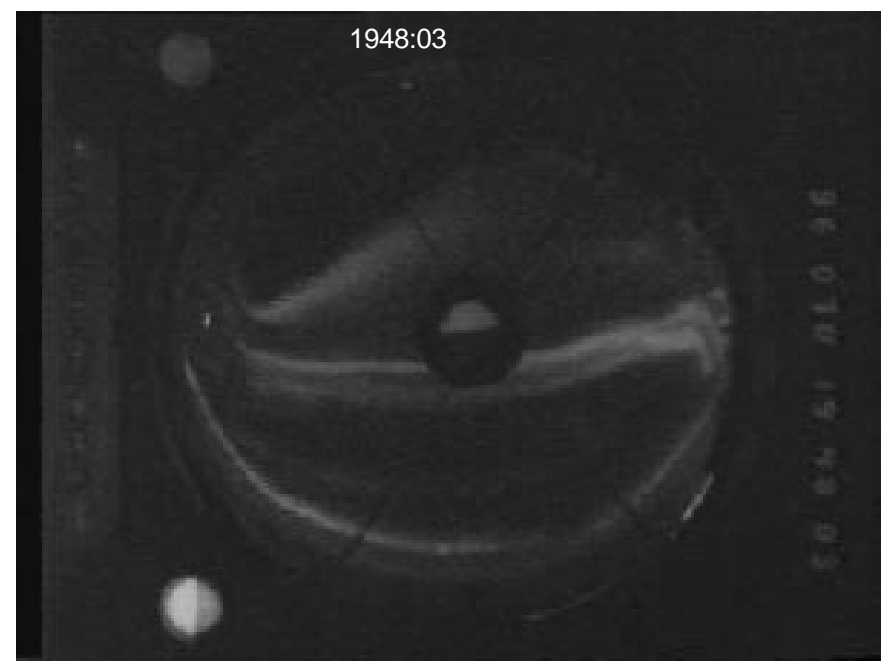

1949:03
Fig. 10. Fading event on 10

March 1996: ASC recordings at (left) KIR and (right) KIL. The fading arc is the brightest one at KIR and the southernmost one at KIL. The fading is visible in the frames around 1948 UT as a local weakening in the auroral luminocity in the eastern part of the arc 


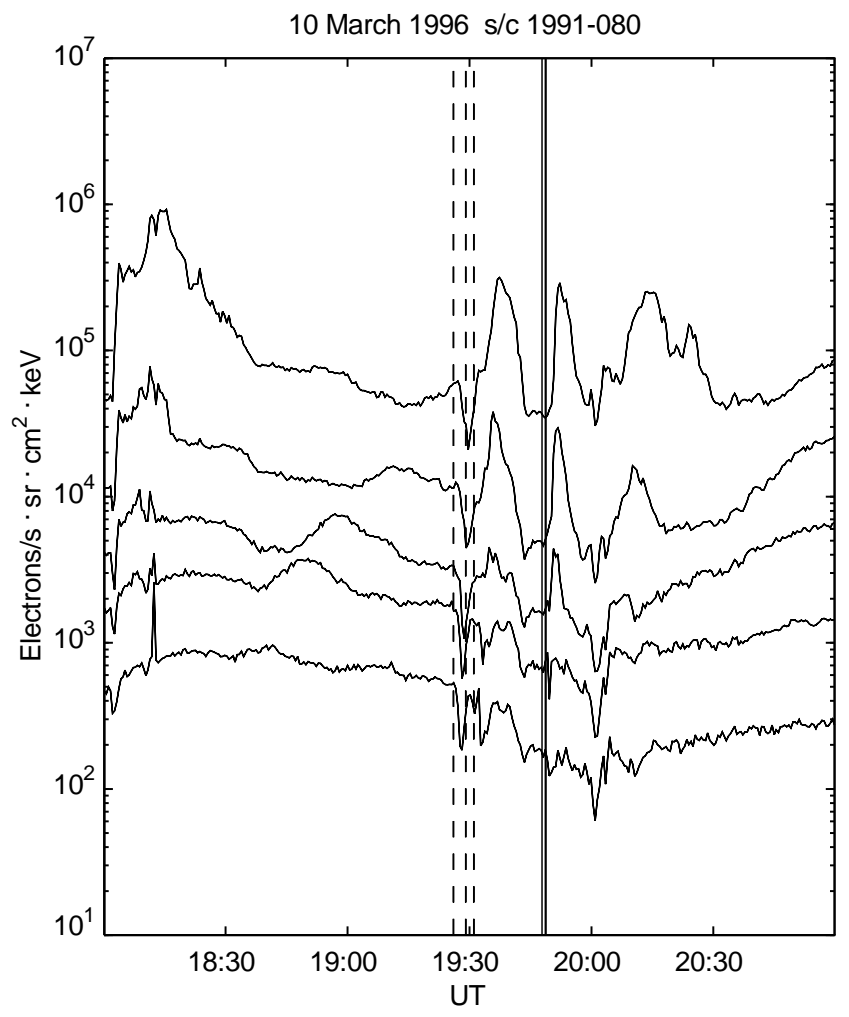

Fig. 11. The fading event on 10 March 1996: differential electron fluxes recorded by the geostationary satellite 1991-080. The vertical solid lines mark the fadings and the breakup time, and the fadings before the pseudo-breakup are marked with the dashed lines. The energy channels are (from top to bottom) 50-75, 75-105, 105-150, $150-225$, and $225-315 \mathrm{keV}$

\section{Overview of the ten fading events}

Table 1 summarizes the typical properties of the fading events: auroral fading lasts typically 2 min (range 50 $420 \mathrm{~s}$ ) and is followed by a local breakup after $2-3 \mathrm{~min}$ (range 0-220 s). In 6 out of 10 cases the fading showed longitudinal dependence (the dark region propagated in an east-west direction or only part of the arc faded), and in eight events the breakup arc had faded earlier. Eight events were recorded in the premidnight sector, 20 24 MLT, and two in the postmidnight sector, 00 02 MLT.

The last four columns of Table 1 characterize the global conditions typically preceeding the fading. The mean $A E$ of the 1-h periods preceding the fadings together with the next $A E_{\max }$ following the fadings are given in columns 8 and 9. As demonstrated by the preceding event studies, auroral fading is typically related to magnetically disturbed periods. In seven cases the auroral electrojets were still disturbed by the previous activity (1-h $A E$ average was above $100 \mathrm{nT}$ ) at the time of the fading. In four out of those seven cases $A E$ was continuously activated (e.g., 26 January 1979) and in three cases $A E$ was recovering from the previous substorm (e.g., 7 March 1988). In particular, event 6 occurred during $A E$ conditions resembling steady mag- netospheric convection (Sergeev et al., 1996). However, the ASC recordings show a clear breakup and westwardtravelling surge also in this case. The fading events 2,5 , and 7 were not immediately followed by onsets in $A E$, although the ASC recordings showed local breakups. The recordings of the northernmost station of the EISCAT Magnetometer Cross (at magn. lat. 67.4 ${ }^{\circ}$ ) reveal that the main magnetic activity related to events 2 and 7 (maximum $\left|\Delta B_{x}\right| \sim 200 \mathrm{nT}$ ) took place at such high latitudes that none of the $A E$ stations could record the disturbance. The breakup in event 5 was similar to the pseudo-breakup recorded on 10 March 1996 at 1932 UT a change in auroral activity without significant magnetic signatures.

In column 10 we indicate the Dst index, which monitored the strength of the ring current during the hour when the fading occurred. The listed values are $\leq-5 \mathrm{nT}$. In particular, the absolute $D s t$ values of the non disturbed events 2,5 , and 7 are $-17,-33$, and -37 , respectively, which are not systematically smaller than in the other cases (with Dst $-57 \ldots-5 \mathrm{nT}$ ).

IMF data recorded by IMP-8 are available for three fading events. In all these cases the IMF $B_{z}$ was negative for an extended period before and during the fadings. The last column (11) of Table 1 lists how long in each case the IMF $B_{z}$ had stayed negative before the fading. As all listed times clearly exceed the propagation times of the solar wind from the satellite to the magnetopause we can conclude that the fadings were not related to sudden changes in the sign of IMF $B_{z}$. Instead, auroral fadings were typically observed when substorm activity was fed by continuous energy input from the solar wind.

We have shown with the selected events that fading can be observed before the very first auroral brightening as well as preceding the expanding substorm aurora. Therefore, defining the exact timing between the fading and the global onset is not a straightforward task, but by comparing ground-based and geostationary observations we can at least list the events where the observed fading did not precede the initial onset: the fading events 9 and 10 (the fadings before the pseudo-breakup) occurred after or simultaneously with the initial global onset (see previous section). The same conclusion can be made for event 3: at the time when the fading was recorded on the ground, AMPTE/IRM magnetic field recordings already show onset signatures (satellite location: $X_{G S M} \sim-14.1 R_{E}, Y_{G S M} \sim 3.8 R_{E}$, and $Z_{G S M} \sim 1.0 R_{E}$ ). In events $1,4,8$, and 10 (fading before the stronger breakup) the exact timing is not possible, as the onset signatures at geostationary orbit were recorded soon after the fadings, and the propagation times of the disturbances from the onset regions to the satellite locations are not known. Thus among seven analyzed events there were at least three in which the observed fading took place after or simultaneously with the global onset. However, as we did not observe the onset we cannot exclude the possibility that the fading preceded the onset in the initial onset location and after that propagated ahead of the expanding bulge.

According to Kauristie et al. (1995), electrojet activity weakened during fading event 8 . Similarly, in five 
other events $(2-4,6$, and 10$)$ the recordings of the EISCAT Magnetometer Cross showed enhancement of the westward electrojet (gradual negative deviation in $B_{x}$ ) during the growth phase and its weakening around the fading time. In the other cases neither clear enhancements nor decreases in the electrojet activity were recorded.

Riometer recordings (data not shown here, for an example see Kauristie et al., 1995) show that the hard $(\geq 40-\mathrm{keV})$ precipitation in events 3 and 8 were enhanced at the beginning of the growth phase and decreased during the fading. Recordings during six other events $(2,4,5,6,7,9)$ were also checked but only weak signatures of the breakup were found, indicating that the activity was mainly outside the narrow riometer beam.

The EISCAT radar was measuring precipitation (particle energies $\leq 20 \mathrm{keV}$ ) during events 7 and 9. In both cases the recordings were made north of the visible arc, and showed a drop in the electron densities around the fading times, similar to event 8 (Fig. 1).

The conductivity of the ionosphere has been suggested to play a critical role in the substorm triggering. Keeping this in mind we wanted to check whether exceptional ionospheric conditions could lead to auroral fading. EISCAT recordings (in the altitude range 87$162 \mathrm{~km}$ ) of event 8 were used for estimating the local height integrated Hall and Pedersen conductivities. The data indicate enhancement first in the Hall conductivity and later, $\sim 3 \mathrm{~min}$ before the fading, in the Pedersen conductivity (data not shown here). The achieved conductivities do not differ much from the average conditions: the Hall conductivities varied between 10 and $17 \mathrm{~S}$, and the Pedersen conductivities between 4.5 and $7.5 \mathrm{~S}$. The average values in the statistical models by Spiro et al. (1982) are 5.5 and 3.3 for Hall and Pedersen conductivity, respectively. The somewhat higher conductivities achieved here can probably be attributed to the vicinity of the auroral arc. The Hall to Pedersen conductivity ratio varied around 2 , which is a typical ratio for the evening sector precipitation (Persson et al., 1992).

\section{Discussion}

Our data indicate that auroral fading precedes in time or space violent changes in auroral precipitation, mostly in association with substorm onset or expansion. In the following we will discuss some theories for auroral-arc formation and substorm onset from the viewpoint of the observations just presented.

\subsection{Fading in the energetic precipitation: strong inductive electric field in the magnetotail}

Pellinen and Heikkila (1984) based their growth-phase arc theory on particle drift calculations, which show that curvature and gradient drifting particles can gain significant amounts of energy when moving along the cross-tail electric field in the neutral sheet region. If the first adiabatic invariant is assumed to be conserved, this mechanism increases nonlinearly the energy parallel to the magnetic field. Consequently the mirroring points of the particles (of both ions and electrons) become lower, and precipitation into the ionosphere increases. A rough estimate using a typically observed cross-tail potential drop and plasma-sheet dimension yields an average energization of the order of $25 \mathrm{keV}$ per particle (Pellinen and Heikkila, 1984). Thus this mechanism controls especially the energetic precipitation.

According to Pellinen and Heikkila, fading in the precipitation prior to the onset is related to a strong inductive electric field opposing the convection electric field. At the end of the growth phase the cross-tail current intensifies exponentially (Ohtani et al., 1992) in the local magnetospheric source region of the auroralarc particles. Consequently the magnetic field changes abruptly, and the inductive electric field strengthens significantly in the same region. This localized inductive electric field decreases the total cross-tail electric field and thus damps the energization of the azimuthally drifting particles, so causing a local fading just before the onset.

As abrupt changes in the magnetotail configuration often take place in the transition from growth to expansion phase, fading due to the inductive electric field should be a common phenomenon. This kind of fading can be better detected with X-ray balloon experiments or meriodional riometer chains than with ASC recordings. In a case-study by Pellinen et al. (1982), hard precipitation $(\geq 40 \mathrm{keV})$ concentrated to a subvisual arc which was southward of the visual arc. At the time when the hard precipitation showed fading, the intensity of the visual arc even seemed to increase. Generally, the distribution of hard precipitation is mainly defined by the magnetospheric energization processes, while the field-aligned potential structures have an important role in controlling the visual arcs. As the potential structures are closely related to the fieldaligned currents (Fridman and Lemaire, 1980), the fading of visual arcs may rather be associated with changes in the field-aligned current distribution.

\subsection{Fading in the visual arc before breakup: azimuthal gradients in field and plasma parameters}

Six of the ten fading events showed longitudinal dependence, which may suggest that the fading process is related to azimuthal gradients in the magnetotail magnetic field or plasma parameters. Furthermore, according to the available $A E$ data, most of the events analyzed here, by Pellinen and Heikkila (1978) and by Morse and Romick (1982), took place during disturbed magnetic conditions. It is likely that the recovery of the previous activity combined with continuous solar wind driving towards a new substorm leads to a disturbed state of the magnetosphere, in which large localized gradients may form.

The equation relating the parallel current to the gradients in plasma pressure and flux tube volume has 
previously been invoked to explain the Region-2 currents flowing toward the Earth in the evening sector and away from the Earth in the morning sector (Vasyliunas, 1979; Birmingham, 1992)

$j_{\|}=\left(B_{i} / B_{e}\right) \mathbf{b} \cdot \nabla P \times \nabla V$,

where $j_{\|}$is the upward current density in the ionosphere, $B_{i}$ and $B_{e}$ are the magnetic field magnitudes in the ionosphere and at the magnetic equator, respectively, $\mathbf{b}=\mathbf{B} / B, P$ is the isotropic ion pressure, and $V$ is the "unit flux tube volume" $\left(\int d s B(s)^{-1}\right)$. A current system in the Region-2 sense follows when the azimuthal gradients of the flux tube volume and plasma pressure point toward magnetic midnight, as can be expected during nondisturbed times [see Tsyganenko (1989) for the magnetic field configuration and Spence et al. (1989) and Korth et al. (1991) for the plasma parameters]. This current system is directed opposite to the substorm current wedge, and is also in the wrong direction to support auroral arcs in the premidnight sector (which are mainly produced by precipitating electrons, i.e., upward current).

Recently, Lyons and Samson (1992) used the same formulation to discuss prebreakup auroral arcs: they argued that during the growth phase the westwarddrifting ions get energized, which causes increased pressure, enhanced cross-tail currents, and field stretching in the evening sector. In this case, the azimuthal gradients of $P$ and $V$ would point duskward near magnetic midnight, and the resulting $j_{\|}$directed away from the ionosphere would feed the auroral arcs.

The azimuthal gradients of $P$ and $V$ could point duskward also after a substorm expansion phase when the magnetotail field is dipolarized, most strongly in the midnight sector. This leads to the familiar substorm current wedge-type current (opposite to the Region-2 current system) which could feed premidnight sector auroral arcs not only during the field recovery, but also during generally disturbed conditions. If under such circumstances the solar-wind driving continues, the near-midnight sector begins to be influenced by a new growth phase, leading to localized stretching of the tail field and thinning of the plasma sheet (McPherron, 1991). This in turn leads to a localized decrease in the duskward pointing azimuthal gradients or even changes their directions (toward the stretched region), which could account for the arc fading before the following new expansion.

For example, in event 1 the substorm onset occurred to the east of the ground-based observations, but slightly to the west of the GEOS 2 meridian. If one assumes that the magnetic field at the onset meridian was the most strongly stretched, the preceding scenario could explain the fading: during the growth phase, when the magnetic field was still stretching, $B_{x}$ and $B_{y}$ at GEOS 2 showed variations consistent with field-aligned currents away from the ionosphere. At the same time, the auroral fadings were observed at the western edge of the most stretched region consistent with a decrease in the duskward-pointing gradient caused by the field stretching.

\subsection{Fading after onset: decreasing the size of the loss cone}

In several cases it was apparent that the global onset had already taken place at the time when the fading was observed. This might suggest that fading can also be associated with the formation of the substorm current wedge at another, not too distant, local-time-sector. In this case fading is observed just ahead of the expanding substorm aurora.

The substorm current wedge leads to dipolarization of the tail field inside the wedge, but, on the other hand, stretches the field even more just outside of it. Because the size of the loss cone is proportional to the magnetic field intensity, stretching of the field (i.e., decreasing $B_{z}$ at magnetic equator) decreases the loss cone, and thus decreases the number of particles able to precipitate into the ionosphere. Thus, the fading could occur as a precursor to the arrival of the substorm current wedge, caused by the effects the field-aligned current has on the equatorial magnetic field. Furthermore, outside the eastern edge of the substorm current wedge, the combination of gradients and parallel currents is such that a substorm current wedge arriving from the west would decrease the outflowing parallel current caused by the growth-phase configuration (Lyons and Samson, 1992), and could thus contribute to the fading there.

For example, in event 3 , fading was observed to the east of the onset region, after the substorm current wedge had formed to the west of the ground station. In this region, both the decreasing loss cone and the dawnward-pointing azimuthal gradients could contribute to the fading.

In one of the fading events we even observed fading preceding the passage of an auroral horn, which is a typical precursor of the expanding substorm aurora (Opgenoorth et al., 1983, and references therein). The velocity of the horn is considerably higher than that of the westward-travelling surge, and thus the horn has been suggested to be a signature of a fast magnetosonic wave which propagates from the onset region across the magnetotail to the plasma-sheet boundary layer (Koskinen et al., 1990). No clear mechanism for fading in front of the horn has been discussed. In analogy we can here only conclude that the common feature of all mechanisms for fading so far discussed is that a new process creating a new type of precipitation initially destroys the previously dominant process or the conditions favoring it.

\subsection{Source region of fading arcs versus geostationary observations}

The recorded fading arcs were mapped to the magnetotail using T89 to investigate the location of their source region in the equatorial plasma sheet. Most of the arcs were observed in the premidnight sector, as indicated before, and they mapped to distances of $X_{G S M} \sim-8 \ldots-16 R_{E}$, which is consistent with previous mapping studies by Pulkkinen et al. (1995) and is about the same region (i.e., within $15 R_{E}$ ) to which the 
most intensive UV auroras map (Elphinstone et al., 1991). The source region of fading arcs, however, is somewhat tailward of the source region of the prebreakup $\operatorname{arcs}\left(X_{G S M} \sim-6 \ldots-10 R_{E}\right)$ analyzed by Samson et al. (1992). Thus the fading arcs most probably did not originate in the region of quasi-dipolar field lines suggested by Samson et al., but further in the tail, in the region where thin current sheets are thought to develop. In this region the growth-phase field signatures are often strongest and the temporal changes in the field configuration are largest. Furthermore, this is typically the region where the substorm onset signatures are first seen (e.g., Pulkkinen et al., 1992). Thus, it seems that the fading arcs are both spatially and temporally related to the region where the substorm onset takes place.

Samson et al. (1992) deduced the source region of prebreakup arcs by analyzing the particle precipitation in the surroundings of the arcs, while the source regions suggested here as well as in the studies by Pulkkinen et al. (1995) and Elphinstone et al. (1991) were based on empirical magnetic field models. A common feature for the cases of Samson et al. was that the arc were within $\mathrm{H} \beta$ auroras caused by energetic proton precipitation. Unfortunately, for the cases analyzed here photometer data are not available, but during the fading events studied by Morse and Romick (1982) $\mathrm{H} \beta$ intensity did not show any significant variations. We do not know whether this observation is typical for fading arcs, in which case the auroral breakup with fading occurring at stretched field lines could be another process than the auroral breakup occurring at quasidipolar field lines.

In the previous sections we have used geostationary satellite observations to monitor the magnetic field configuration in the tail and to estimate the mutual timing of the fading and the initial onset. The fading arcs cannot be directly related with the abrupt electron flux decreases observed at the geostationary orbit, but nor can we exclude the possibility that these two effects, e.g., have the same cause. Auroral fadings seem not to have a one-to-one correspondence with DEH signatures: a DEH is a relatively common phenomenon (Shuktina et al., 1996), but in the cases analyzed here clear DEH signatures were observed only in two of those five events with LANL data available. On the other hand, the connection between the fading and the flux variations modifying the cigar-type electron distributions at GEOS 2 (c.f. Sect. 3.2) is more difficult to rule out, although we do not know of any obvious mechanism relating these two effects.

\subsection{The role of the ionosphere}

As the fadings typically occur during active periods, it is possible that the phenomenon is connected with the changes in the plasma composition in the inner-tail plasma sheet. During substorms, ionospheric oxygen is pumped out from the ionosphere such that the relative proportion of oxygen and hydrogen increases substantially (Daglis et al., 1994). This may lead to dynamical behavior of the tail, which is different from what takes place during isolated substorms (Baker et al., 1982).

The ionosphere may control the onset triggering and fading also more directly: based on their MHD simulations, Janhunen et al. (1995) suggested that fading and the following breakup are signatures of compressional MHD oscillations of the near-Earth tail caused by enhanced convection. The role of the ionosphere in either damping or amplifying these oscillations appeared to be crucial: when the simulation was repeated without ionospheric feedback only large-scale pulsations without identifiable breakups or fadings took place.

\section{Summary and conclusions}

The main focus of this study was to select clear events with observations from several regions and instruments to report on the typical conditions under which auroral fading takes place just before the local breakup. Prior studies of the fading have concentrated on ionospheric observations; here we make a first attempt to connect the auroral variations to magnetospheric observations. The results bear significance both to the detailed configuration immediately prior to the substorm onset as well as to the onset process itself.

We noticed that the auroral fading can occur before the global onset, as previously reported, but also after the onset as a precursor to the approaching substorm current wedge at a location not too distant from the onset location. In the latter case, however, as we did not observe the onset, we cannot exclude the possibility that the fading preceded the onset in the initial onset location and after that propagated ahead of the expanding bulge.

The activity indices support the conclusion that the fadings are often related to growth phases developing under disturbed conditions, after prior substorm activity. These periods are characterized by continuously high levels of $A E$ activity, but the geostationary data indicate that a clear growth-phase process is in progress. IMF data recorded by IMP-8 are available for three fading events, and in all these cases the fading was observed when substorm activity was fed by continuos energy input from the solar wind.

Mappings with magnetic field models suggest that the source region of the fading arcs is in a region where thin current sheets typically develop and the substorm onset signatures are often first seen. We established the close spatial relationship between the fading and the local breakup also at the ionospheric end: in eight of the ten events analyzed here the arc which broke up had faded earlier.

As a dramatic effect the auroral fading is a widely recognized phenomenon, but we have noticed that in the standard mode ASC recordings with one frame per minute visual fading cannot be detected frequently. However, the recordings with 10-s resolution suggested that the fadings can take place within a few tens of seconds, which suggests that (1) we may have missed many fading events because of too low imaging resolu- 
tion, and (2) the times given here in Table 1 represent an upper limit to the visual fading times.

The exact cause of fading still remains an open question, but we conclude that most probably there are several mechanisms leading to the fading events observed under variable geomagnetic conditions and in several different energy regimes. Here we discuss three possible scenarios for the fadings, one related to the azimuthal gradients caused by the growth-phase-associated field stretching, a second related to the loss-cone changes caused by the forming current wedge, and a third related to the strong inductive electric field caused by the abrupt magnetic field changes during the late growth phase.

The following few years with extensive ground-based facilities running in parallel with the ISTP spacecraft will hopefully help us to verify these scenarios. The new ground-based instruments, especially ASCs and riometers, with continuous high-time-resolution recordings, will yield new information on the occurrence and energy coverage of the fading effect. Although POLAR and Interball imagers are not capable of resolving structures in arc-scale, they can show the location and time of the initial onset and thus provide an opportunity to estimate more carefully the mutual timing of the fading and the onset. With several ISTP satellites surveying various magnetospheric regions one could even find a lucky coincidence with ground-based observations of fading and satellite recordings in the source region of the fading arc. Such observations would be an ideal input when considering different arc-formation mechanisms. Thus the ISTP observations will hopefully parse some of the remaining gaps in our understanding of onset-related phenomena. The findings of this paper can help to provide temporal and spatial constraints to different onset conditions, as well as shed light on substorms occurring under more complex circumstances.

Acknowledgements. V. Sergeev and H. Koskinen are acknowledged for their careful reading of the manuscript. The magnetometer data from the EISCAT Cross were studied with the program package developed by A. Viljanen. The EISCAT radar data were received from P. Pollari (University of Oulu, Finland) and I. Häggström (IRF Kiruna, Sweden) who also provided Kiruna magnetograms. The riometer data were provided by H. Ranta (Geophysical Observatory, Sodankylä, Finland), and GEOS 2 data by A. Pedersen (ESA, ESTEC). The particle data from Los Alamos instruments were retrieved from the automated data base of LANL with the patient guidance of G. D. Reeves. Plots of AMPTE/IRM magnetometer data were provided by $\mathrm{H}$. Lühr. IMP-8 magnetometometer data were received from the archives of NASA/GSFC. The EISCAT Scientific Association is supported by the SA of Finland, CNRS of France, MPG of Germany, NAF of Norway, NF of Sweden, and SERC of the United Kingdom. The work of K.K. was supported by the Academy of Finland.

Topical Editor, D. Alcaydé thanks S.-I. Ohtani, J. E. Borovsky and C. Jacquey for their help in evaluating this paper.

\section{References}

Baker, D. N., P. R. Higbie, E. W. Hones Jr., and R. D. Belian, High-resolution energetic particle measurements at $6.6 \mathrm{Re}, 3$. Low-energy electron anisotropies and short-term substorm predictions, J. Geophys. Res., 83, 4863-4868, 1978.
Baker, D. N., E. W. Hones Jr., D. T. Young, and J. Birn, The possible role of ionospheric oxygen in the initiation and development of plasma sheet instabilities, Geophys. Res. Lett., 9, 1337-1340, 1982.

Baker, K. B., and S. Wing, A new magnetic coordinate system for conjugate studies at high latitudes, J. Geophys. Res., 94, 91399143, 1989.

Birmingham, T. J., Birkeland currents in an anisotropic, magnetostatic plasma, J. Geophys. Res., 97, 3907-3917, 1992.

Daglis, I. A., S. Livi, E. T. Sarris, and B. Wilken. Energy density of ionospheric and solar wind origin ions in the near-Earth magnetotail during substorms, J. Geophys. Res., 99, 56915703, 1994.

Elphinstone, R. D., D. Hearn, J. S. Murphree, and L. L. Cogger, Mapping using the Tsyganenko long magnetospheric model and its relationship to Viking auroral images, J. Geophys. Res., 96, 1467-1480, 1991.

Fridman, M., and J. Lemaire, Relationship between auroral electron fluxes and field aligned electric potential differences, J. Geophys. Res., 85, 664-670, 1980.

Galperin, Y. I., and Y. I. Feldstein, Auroral luminosity and its relationship to magnetospheric plasma domains, in Auroral physics, ed. C.-I. Meng, M. J. Rycroft, and L. A. Frank, Cambridge University Press, New York, pp. 207-222, 1991.

Janhunen, P., T. I. Pulkkinen, and K. Kauristie, Auroral fading in ionosphere-magnetosphere coupling model: implications for possible mechanism, Geophys. Res. Lett., 22, 2049-2052, 1995.

Kauristie, K., Statistical fits for auroral oval boundaries during the substorm sequence, J. Geophys. Res., 100, 21 885-21 895, 1995.

Kauristie, K., T. I. Pulkkinen, R. J. Pellinen, P. Janhunen, A. Huuskonen, A. Viljanen, H. J. Opgenoorth, W. J. Heikkila, and D. N. Baker, Analysis of the substorm trigger phase using multiple ground-based instrumentation, Geophys. Res. Lett., 22, 2065-2068, 1995.

Kauristie, K., T. I. Pulkkinen, R. J. Pellinen, and H. J. Opgenoorth, What can we tell about global electrojet activity from a single meridional magnetometer chain? Ann. Geophysicae, 14, 11771185, 1996.

Korth, A., Z. Y. Pu, G. Kremser, and A. Roux, A statistical study of substorm onset conditions at geostationary orbit, in Magnetospheric substorms, Geophysical Monograph 64, American Geophysical Union, 343-351, 1991.

Koskinen, H. E. J., T. I. Pulkkinen, and R. J. Pellinen, Mapping of the auroral horn into the magnetotail, Planet. Space Sci., 38, 1179-1186, 1990.

Lühr, H., The IMAGE magnetometer network, STEP Intern., 4 (10), 4-6, 1994.

Lühr, H., S. Thürey, and N. Klöcker, The EISCAT-Magnetometer Cross, technical aspects - first results, Geophys. Surv., 6, 305315, 1984.

Lyons, R. L., and J. C. Samson, Formation of the stable auroral arc that intensifies at substorm onset, Geophys. Res. Lett., 19, 21712174, 1992.

McPherron, R. L., Physical processes producing magnetospheric substorms and magnetic storms, in Geomagnetism, vol 4, ed. J.A. Jacobs, Academic Press, San Diego, pp. 593-739, 1991.

Morse, T. H., and G. J. Romick, The fluctuation and fading of auroral arcs preceding auroral substorm onsets, Geophys. Res. Lett., 9, 1065-1068, 1982.

Newell, P. T., S. Wing, C.-I. Meng, and V. Sigillito, The auroral oval position, structure, and intensity of precipitation from 1984 onward: an automated on-line data base, J. Geophys. Res., 96, 5877-5882, 1991.

Ohtani, S., K. Takahashi, L. J. Zanetti, T. A. Potemra, and R. W. McEntire, Initial signatures of magnetic field and energetic particle fluxes a tail reconfiguration: explosive growth phase, J. Geophys. Res., 97, 19311-19324, 1992.

Olsson, A., A. I. Eriksson, and P. Janhunen, On the current-voltage relationship in the auroral breakups and westward travelling surges, Ann. Geophysicae, 14, 1265-1273, 1996. 
Opgenoorth, H. J., R. J. Pellinen, W. Baumjohann, E. Nielsen, G. Marklund, and L. Eliasson, Three-dimensional current flow and particle precipitation in a westward travelling surge (observed during the Barium-GEOS rocket experiment), $J$. Geophys. Res., 88, 3138-3152, 1983.

Pajunpää, A., and M. Syrjäsuo, A new Finnish all-sky camera chain, in Proc. planning meeting for joint studies with Oersted, the EISCAT incoherent scatter radars and other ground-based instruments, Sodankylä, 18.-19.4.1996, The Finnish Academy of Science and Letters, Report No. 54, (Eds. H. Ranta, E. Turunen and M. Hämäläinen), pp. 83-88, 1996.

Pellinen, R. J., W. Baumjohann, W. J. Heikkila, V. A. Sergeev, A. G. Yahnin, G. Marklund, and A. O. Melnikov, Event study on pre-substorm phases and their relation to the energy coupling between solar wind and magnetosphere, Planet. Space Sci., 30, 371-388, 1982.

Pellinen, R. J., and W. J. Heikkila, Observations of auroral fading before breakup, J. Geophys. Res., 83, 4207-4217, 1978.

Pellinen, R. J., and W. J. Heikkila, Inductive electric fields in the magnetotail and their relation to auroral and substorm phenomena, Space Sci. Rev., 37, 1-61, 1984.

Persson, M. A. L., H. J. Opgenoorth, and R. D. Elphinstone, On the difference of ionospheric conductances in the morning and evening sectors of the auroral oval, in Proc. First Int. Conf. Substorms, Kiruna, Sweden, 23-27 March 1992, ESA SP-335, 29-31, 1992 .

Pulkkinen, T. I., H. Koskinen, and R. J. Pellinen, Mapping of auroral arcs during substorm growth phase, J. Geophys. Res., 96, 21087-21094, 1991.

Pulkkinen, T. I., D. N. Baker, R. J. Pellinen, J. Büchner, H. E. J. Koskinen, R. E. Lopez, R. Dyson, and L. A. Frank, Particle scattering and current sheet stability in the geomagnetic tail during the substrom growth phase, J. Geophys. Res., 97, 1928319297, 1992
Pulkkinen, T. I., D. N. Baker, R. J. Pellinen, J. S. Murphree, and L. A. Frank, Mapping of the auroral oval and individual arcs during substorms, J. Geophys. Res., 100, 21987-21994, 1995.

Ranta, H., A. Ranta, P. N. Collis, and J. K. Hargreaves, Development of the auroral absorption substorm: studies of pre-onset phase and sharp onset using and extensive riometer network, Planet. Space Sci., 29, 1287-1313, 1981.

Samson, J. C., L. R. Lyons, P. T. Newell, F. Creutzberg, and B. Xu, Proton aurora and substorm intensifications, J. Geophys. Res., 97, 6541-6548, 1992.

Sergeev, V. A., T. Bösinger, R. D. Belian, G. D. Reeves, and T. E. Cayton, Drifting holes in the energetic electron flux at geosynchronous orbit following substorm onset, J. Geophys. Res., 97, 6541-6548, 1992.

Sergeev, V. A., R. J. Pellinen, and T. I. Pulkkinen, Steady magnetospheric convection: a review of recent results, Space Sci. Rev., 75, 551-604, 1996.

Shuktina, M. A., V. A. Sergeev, L. I. Vagina, R. Rasinkangas, T. Bösinger, K. Mursula, G. Kremser, A. Korth, G. D. Reeves, and H. J. Singer, Drifting electron holes observed by CRRES spacecraft, in Proc. Third Int. Conf. Substorms, Versailles, France, 12-17 May 1996, ESA SP-389, 591-596, 1996.

Spence, H. E., M. Kivelson, and R. J. Walker, Magnetospheric plasma pressures in the midnight meridian: observations from 2.5 to $35 R_{E}$, J. Geophys. Res., 89, 5264-5272, 1989.

Spiro, R. W., P. H. Reiff, and L. J. Maher Jr, Precipitating electron energy flux and auroral zone conductances - an empirical model, J. Geophys. Res., 87, 8215-8227, 1982.

Tsyganenko, N. A., Magnetospheric magnetic field model with a warped tail current sheet, Planet. Space Sci., 37, 5-20, 1989.

Vasyliunas, V. M., Mathematical models of magnetospheric convection and its coupling to the ionosphere, in Particles and fields in the magnetosphere, Ed. B.M. McCormac, D. Reidel Dordrecht, pp. 60-71, 1979. 